\title{
Tax Policy and Toxic Housing Bubbles in China
}

\author{
Pengfei Jia and King Yoong Lim* \\ This version: June, 2020
}

\begin{abstract}
This paper explores the effects of a government tax policy in a growth model with economic transition and toxic housing bubbles applied to China. Such a policy combines taxing entrepreneurs with a one-time redistribution to workers in the same period. Under the tax policy, we find that the welfare improvement for workers is non-monotonic. In particular, there exists an optimal tax at which social welfare is maximized. Moreover, we consider the welfare effects of setting the tax at its optimum. We show that the tax policy can be welfare-enhancing, comparing to the case without active policies. The optimal tax may also yield a higher level of welfare than the case even without housing bubbles. In addition, our simple numerical exercise shows that the optimal tax rate is about 23 percent, and social welfare is significantly improved with such a tax policy. Finally, we extend the benchmark economy to a multi-period setting and calibrate the model to China. Our results show that a 20 percent tax rate can speed up economic transition and increase output growth. Between 1998 and 2012, aggregate consumption is 4.86 percent higher under active tax policies.
\end{abstract}

JEL Classification Numbers: O18 P31 R21 R28.

*Jia: Corresponding author, School of Economics, Nanjing University, China. E-mail address: pengfei@nju.edu.cn; Lim: Nottingham Business School, Nottingham Trent University, United Kingdom. We thank Feng Dong, Jiechao Gao, Christoph Himmels, and Wentao Ma for useful comments and discussions. We also thank Pengfei Wang (the editor in charge) and one anonymous referee for many helpful suggestions. Financial support from National Natural Science Foundation of China (No.71573206) is gratefully acknowledged. The views expressed in this paper and any errors are our own. 


\section{Introduction}

Over the past decades, the Chinese housing sector has gone through a spectacular boom. In China's top tier cities, which include Beijing, Shanghai, Guangzhou, and Shenzhen, real housing prices have grown at an annual rate of 13.1 percent from 2003 to 2013 (Fang et al. 2015). Housing prices have soared in tier-2, tier-3, and tier-4 Chinese cities as well. ${ }^{1}$ Yet the dramatic housing boom has been accompanied by a smaller increase in income: data for 35 major Chinese cities show the average real housing prices grew at 17 percent over the past decade, whereas the average income growth rate was only 11 percent (Chen and Wen 2017). This fact is at odds with the predictions of standard neoclassical model, which requires that housing prices grow at most as fast as aggregate income. If housing prices continue to grow, at a higher rate than that of average income, over time, housing would become increasingly unaffordable for Chinese households, especially for those living in top tier cities (Chen et al. 2019). In fact, for example, as of year 2016, a 90-square-meter apartment in Beijing or Shanghai costs more than 25 times average household income (Glaeser et al. 2017).

The dramatic size of the Chinese housing boom has left the global economic and policy communities a question that whether Chinese real estate is a bubble waiting to burst. Indeed, the fast rise of housing prices is widely viewed as a clear illustration of the dangers associated with speculative bubbles. Despite the housing boom, vacancy rates across Chinese major cities are large and persistent, at around one quarter, hence leading to a phenomenon dubbed as "ghost towns". These suggest the presence of housing bubbles. ${ }^{2}$

\footnotetext{
${ }^{1}$ China's cities are typically divided into four categories or tiers, based on the level of economic development. See Fang et al. (2015) for a clear classification.

${ }^{2}$ In the small but growing literature studying China's housing boom, it is worth noting that some papers suggest Chinese cities may not experience housing bubbles. For example, Garriga et al. (2017) emphasize the importance of structural transformation and the resulting rural-urban migration in accounting for the upward trend in housing price movements in China. Also, Glaeser et al. (2017) analyze the determinants of demand and supply of housing in China and conclude that a housing
} 
In the literature, most models of rational bubbles adopt the overlapping generations framework (Samuelson 1958; Tirole 1985; Weil 1987; Grossman and Yanagawa 1993). It is well known that rational asset bubbles cannot arise in the simple infinite-horizon model because the transversality condition rules out exploding asset prices path (Santos and Woodford 1997). However, it is important to note that recent studies show that bubble can exist in the infinite-horizon economy under certain conditions, such as introducing trading frictions or borrowing constraints. ${ }^{3}$ And bubbles can exist in various assets, see Dong et al. (2018) for firm bubbles and Dong et al. (2019b) for household housing bubbles.

In terms of welfare implications, the conventional wisdom is that bubbles are welfare improving because of dynamic inefficiency. However, in terms of anecdotal evidence, bubbles can be potentially costly and are often accompanied with crisis and a sharp drop in household wealth when they burst. In fact, policymakers and researchers are more concerned about the welfare costs of bubbles. ${ }^{4}$ For example, Dong et al. (2019c) conduct the positive and normative analysis of the resource-consuming cryptocurrencies in an infinite-horizon economy.

Specific to China's high housing price puzzle, an interesting paper is by Chen and Wen (2017), who propose a theory to explain the paradoxical housing boom in Chinanamely real housing prices outpacing income; high vacancies; and a high rate of return to capital. Their model framework is an extension of Song et al. (2011) with an intrinsically valueless housing asset,${ }^{5}$ which is shown to be important to study growcrash is not inevitable.

${ }^{3}$ Notable examples include Kocherlakota (1992, 2008, 2009), Caballero and Krishnamurthy (2006), Hellwig and Lorenzoni (2009), Farhi and Tirole (2012), Martin and Ventura (2012), Miao and Wang (2012, 2014, 2015, 2018), Wang and Wen (2012), Miao et al. (2015a, 2015b, 2016), Hirano and Yanagawa (2017), Dong et al. (2018), Dong and Xu (2019), Dong et al. (2019c), and Dong et al. (2020). See Miao (2014) for a comprehensive survey.

${ }^{4}$ In different model environments, potential costs may include volatility, fire sales after the collapse of bubbles (Caballero and Krishnamurthy 2006), and misallocation of resources in the presence of market distortions (Miao et al. 2015b).

${ }^{5}$ Song et al. (2011) is an influential paper, which can endogenously generate and quantitatively 
ing bubbles and to understand China's prolonged paradoxical housing boom. Their simulation results show that the model can quantitatively replicate China's housing price dynamics over the past decade fairly well and still be consistent with many other salient features of the Chinese economy. What's more, unlike many traditional bubble models where bubbles are welfare-improving, they show that housing bubbles are welfare-reducing and toxic. Specifically, in the model, the growing bubble crowds out productive investment, prolongs economic transition, and thus reduces social welfare. Recently, Dong et al. (2019a) use a New Keynesian dynamic model with a rich modelling of firms' portfolio choice between physical and financial investment. They find that a rise in house prices can depress the firm's demand for productive capital due to the crowding-out effect.

Since a housing bubble reduces welfare, it is natural to ask what policies can be used to reduce the negative impact of housing bubbles and possibly improve social welfare? We find that a tax policy, which combines taxing entrepreneurs with a one-time redistribution to workers in the same period, may address this issue. The overarching objective of our study is to explore the welfare effects of a government tax policy in a growth model with economic transition and toxic housing bubbles applied to China.

One strand of literature discusses the impact of government policies on affecting bubbles (see Galí 2014; Miao et al. 2015b, 2020; Dong and Xu 2019; Dong et al. 2020). For example, in an OLG model with nominal rigidities, Galí (2014) examines the impact of alternative monetary policy rules on a rational asset price bubble. He finds that a systematic increase in interest rates in response to a growing bubble is shown to enhance the fluctuations in the latter, through its positive effect on bubble growth. This calls into question the theoretical foundations of the case for "leaning against

account for some important features of China's economic transition, such as high output growth, sustained returns on capital, reallocation within the manufacturing sector, and a large trade surplus. Their growth model is therefor widely adopted in studying China's fast growth and economic transition, see, for example, Song et al. (2014), Chang et al. (2015), and Chen and Wen (2017). 
the wind" monetary policies. ${ }^{6}$ Dong et al. (2020) address the dynamic interactions between monetary policy and asset bubbles. Using a dynamic NK framework, they find that the leaning-against-the-wind interest rate policy reduces bubble volatility, but could raise inflation volatility. Whether monetary policy should respond to asset bubbles depends on the particular interest rate rule and exogenous shocks. Dong and Xu (2019) analyze the time-varying bailout policy for asset bubbles in an infinitehorizon production economy. They find that asset bubbles alleviate firms' financial constraints and enhance investment efficiency by providing liquidity. But bubbles are vulnerable to market sentiment and are resource-consuming. In the presence of this trade-off, the optimal bailout policy is leaning against the wind, striking a balance between the crowding-in and crowding-out effect.

There is another strand of literature on Chinese housing markets through the lens of macroeconomic models (see Zhang 2016; Zhang 2017; Dong et al. 2019a, 2019b). For instance, Zhang (2017) proposes a quantitative explanation of the Chinese housing boom, based on the upward transition in household wealth from a low initial condition, interacted with liquidity constraints. This framework explains the large increase in housing prices and generates an investment motive in holding housing, which helps rationalize the high Chinese household saving rate puzzle. Dong et al. (2019b) introduce housing into a standard incomplete financial market model. They empirically and quantitatively document the driving force of the recent Chinese housing boom through the lens of a household's demand for safe assets. They show that, in the presence of an underdeveloped financial market, housing becomes a desirable saving device as the economy becomes more uncertain.

However, most the theoretical works along this line focus on why the housing price

\footnotetext{
${ }^{6}$ Miao et al. (2020) revisit Galí's (2014) by extending his model to incorporate persistent bubble shocks. When deriving the unique forward-looking minimum stable variable (MSV) solution around an unstable bubbly steady state, they obtain results that are consistent with the conventional views: leaning-against-the-wind policy reduces bubble volatility and is optimal.
} 
level is so high (see Zhao 2015 and Garriga et al. 2017), instead of asking why housing prices have been able to grow faster than income. ${ }^{7}$ Our analysis forms a bridge between the two strands of studies. To the best of our knowledge, our paper is the first to design and study the impact of government policies on reducing China's housing bubbles and improving welfare.

Specifically, we first show that the worker's lifetime utility is non-monotonically increasing with the tax policy. In particular, there exists a closed-form optimal tax rate, at which worker's welfare is maximized. This non-monotonic relationship between welfare and the tax rate is due to a trade-off effect of the tax policy. On the one hand, a positive tax rate increases workers' welfare as they receive real resources transferred to consumption every period. However, such a tax policy also implies a fall in capital accumulation, resulting in a decrease of productive resources. Second, we define social welfare as the sum of entrepreneur's and worker's lifetime utilities. Our results show that there exists an optimal tax rate, at which social welfare is maximized.

While it is immediately obvious that such a tax regime would reduce entrepreneur's welfare but increase worker's welfare, if the losses of entrepreneurs are dominated by the gains of workers, an active tax policy can improve social welfare by making the housing bubble less toxic to workers. We show analytically that under certain conditions, the tax policy can be welfare-enhancing, comparing to the case without active policies. The optimal tax policy may also yield a higher level of welfare than the case even without housing bubbles. In addition, our simple numerical exercise shows that, under a large range of realistic parameter values, the optimal tax rate changes from 21 percent to 23 percent. More importantly, the welfare gains by workers are quantitatively large whereas the welfare losses by entrepreneurs are relatively small. There are therefore

\footnotetext{
${ }^{7}$ At the same time, it is worth noting that there is a growing empirical literature on housing prices in China. For instance, see Wang (2011), Wu et al. (2012), Wang and Zhang (2014), Wu et al. (2014), Huang et al. (2015), Wu et al. (2015), and Wu et al. (2016), among others.
} 
always welfare gains when the tax policy is active. Finally, we extend the benchmark economy to a multi-period setting and calibrate the model to Chinese economy. This is aimed at exploring the quantitative effects of active tax policies on the real economy. We find that a 20 percent tax policy, by making housing bubbles less toxic, can speed up economic transition, mitigate the negative effects of resource misallocation, and generate higher economic growth. Between 1998 and 2012, aggregate consumption is 4.86 percent higher than in the economy without tax policies.

Our paper is organized as follows. Section 2 describes a simple two-period growth model and characterizes the equilibrium, as well as the model's qualitative implications. Section 3 investigates the welfare implications of an explicit government tax policy, both on workers and entrepreneurs. Section 4 calibrates the model to China, and discusses quantitative implications of the tax policy. Section 5 concludes with remarks for further research. The Appendix contains proofs of all Lemmas and Propositions.

\section{The benchmark model}

This section describes our model economy and discusses its key assumptions. Our purpose is to study the Chinese housing market and the effects of an active tax policy on social welfare. Such a policy combines taxing entrepreneurs with a one-time redistribution in the same period. The redistribution is implemented by a lump-sum tax on entrepreneurs who are the marginal investors in the housing market and a lump-sum transfer to workers who are adversely affected by the housing bubbles. The tax policy can be interpreted broadly as a corporate tax, the distortionary taxation toward private industry, or various government policies that restrict the growth of private firms. ${ }^{8}$

\footnotetext{
${ }^{8}$ As noted by Chen and Wen (2017), in reality, the Chinese government increases the tax burden of private firms over time. For example, in 2007, the state government issued a document (the 39th Decree), which requests a transition from preferential corporate income tax rates to legal tax rates. Accordingly, those who enjoyed a 15 percent corporate income tax rate before 2008 would face
} 
Our analyses are based on the OLG model of Chen and Wen (2017), which is consistent with the institutional background and stylized empirical facts about China and its housing market behavior. In particular, the model framework is an extension of Song et al. (2011) with an intrinsically valueless housing asset. ${ }^{9}$ For simplicity, the model excludes low-income households (workers) from the housing market because their participation has only a level effect but no growth effects on the housing prices.

In contrast with many traditional bubble models (e.g., Tirole 1985) where bubbles are welfare-improving due to dynamic inefficiency, housing bubbles in our model can exist even when the economy is dynamically efficient, owing to a wedge between social and private rates of return to capital. ${ }^{10}$ As a result, bubbles can reduce, rather than increase, social welfare. In this model, housing bubbles are toxic in that they can crowd out productive investment, create resource misallocation, and reduce the welfare of both entrepreneurs and workers. ${ }^{11}$ This then warrants policy intervention.

The model economy is populated by overlapping generations (OLG) of two-period lived agents who work in the first period and live off savings in the second period. Agents have heterogeneous skills. In each cohort, half of the population consists of workers without entrepreneurial skills and the other half consists of entrepreneurs.

gradually progressive tax rates of 18 percent, 20 percent, 22 percent, 24 percent, and 25 percent for each year between 2008 and 2012, respectively. In this OLG framework, we interpret it as a one-off lump-sum tax accompanied by a one-time redistribution.

${ }^{9}$ We adopt the OLG modelling device of Song et al. (2011) and Chen and Wen (2017), instead of an infinitely-horizon model, because these models can endogenously generate and quantitatively account for some important features of China's economic transition, such as sustained return on capital, labor reallocation within the manufacturing sector, and growing housing bubbles, which are key to our policy analysis.

${ }^{10}$ In a similar vein, Farhi and Tirole (2012) argue that agency frictions drive a wedge between the social rate of returns to capital and the equilibrium rate of return. As a result, bubbles exist even when the economy is dynamically efficient, and bubbles do not typically lead to Pareto improvements. Early studies, including Woodford (1990), Kocherlakota (1992), Azariadis and Smith (1993), and Santos and Woodford (1997), also show that bubbles could arise in dynamically efficient economies if there are financial frictions (e.g., borrowing constraints and adverse selection).

${ }^{11}$ This feature is particularly relevant to the current Chinese economy. For example, Chen et al. (2017) provide empirical evidence that increases in housing prices tend to crowd out firms' fixed capital formation in China, which in turn leads to TFP losses due to misallocation of capital. 
Entrepreneurial skills are inherited from parents; for simplification and without loss of generality, we do not allow transition between social classes. The total population, $N_{t}$, grows at an exogenous rate $v$; hence, $N_{t+1}=(1+v) N_{t}$.

\subsection{Technology}

There are two production sectors and thus two types of firms, both requiring capital and labor. Labor is perfectly mobile across the two sectors but capital is not. The first sector consists of financially integrated neoclassical firms, F-firms, which, for simplicity, are owned by a representative financial intermediary (e.g., a state-owned bank). The second sector is a newly emerging private sector composed of unconventional entrepreneurial firms, E-firms, operated by entrepreneurs. E-firms are owned by old (parent) entrepreneurs, who are residual claimants on profits, and they hire their own children as managers. Workers can choose to work for either type of firm.

The key assumptions are that E-firms are more productive than F-firms but, due to asymmetric financial imperfections, E-firms are borrowing constrained - they cannot borrow from each other or from any other sources. As a result, E-firms must self-finance capital investment through their own savings. In contrast, F-firms can rent capital from their representative financial intermediary at a fixed interest rate. Accordingly, F-firms can survive in the short run despite inferior technology. Over time, however, labor will gradually reallocate from F-firms to E-firms as the capital stock of E-firms expands. Thus, the economy features a transition stage during which F-firms and E-firms coexist, but the F-sector is shrinking and the E-sector is expanding. When the transition ends, only E-firms exist and the economy becomes a representative-agent growth model with neoclassical features. ${ }^{12}$ Matching the model specification to China, it is obvious that

\footnotetext{
${ }^{12}$ Note that, following Song et al. (2011) and Chen and Wen (2017), the term "transition" is different from the convention in the neoclassical growth model, where transition means the dynamic path from an initial state towards the steady state. In our paper, this conventional transition phase
} 
F-firms can be interpreted as state-owned enterprises, while E-firms are private firms.

The technology of F-and E-firms are described, respectively, by the following production functions:

$$
y_{t}^{F}=\left(k_{t}^{F}\right)^{\alpha}\left(A_{t} n_{t}^{F}\right)^{1-\alpha}, y_{t}^{E}=\left(k_{t}^{E}\right)^{\alpha}\left(A_{t} \chi n_{t}^{E}\right)^{1-\alpha}
$$

where $y, k$, and $n$ denote per capita output, capital stock, and labor, respectively. The parameter $\chi>1$ captures the assumption that E-firms are more productive than F-firms. Technological growth in both sectors is constant and exogenous, given by $A_{t+1}=(1+z) A_{t}$

\subsection{Worker's problem}

We now analyze agents' savings problem. Young workers earn a wage $w$ and deposit their savings with the representative bank, receiving a gross interest rate $R$. In addition, with an active tax policy, the tax revenue $T$ is transferred in a lump-sum manner to the current young for consumption. Without loss of generality, we also assume that workers do not speculate in the housing market, since allowing workers to invest in housing market does not change our main results. ${ }^{13}$

The worker's consumption-saving problem is:

$$
\max \log c_{1 t}^{w}+\beta \log c_{2 t+1}^{w}
$$

subject to $c_{1 t}^{w}+s_{t}^{w}=w_{t}+T_{t}$ and $c_{2 t+1}^{w}=s_{t}^{w} R$, where $w_{t}$ is the market wage rate; shows up after the F-sector disappears. To avoid confusion, we call this neoclassical transition period "post-transition" stage.

${ }^{13}$ Indeed, in the quantitative analysis section later, we also consider the case where workers are allowed to speculate in the housing markets. We find that the growth rate of housing prices is unaffected. This is because of the equilibrium growth rate of housing prices in the model is determined by the rate of return to capital of the entrepreneurs, who act as the marginal investors in the "bubbly equilibrium". 
$c_{1 t}^{w}, c_{2 t+1}^{w}$, and $s_{t}^{w}$ denote consumption when young, consumption when old, and the worker's savings, respectively. This yields the optimal savings $s_{t}^{w}=\zeta^{w}\left(w_{t}+T_{t}\right)$, where $\zeta^{w} \equiv\left(1+\beta^{-1}\right)^{-1}$.

\subsection{The F-firm's problem}

In each period, an F-firm maximizes profits by solving the following problem:

$$
\max _{k_{t}^{F}, n_{t}^{F}}\left(k_{t}^{F}\right)^{\alpha}\left(A_{t} n_{t}^{F}\right)^{1-\alpha}-w_{t} n_{t}^{F}-R k_{t}^{F}
$$

Profit maximization implies that $R$ equals the marginal product of capital and that wages equal the marginal product of labor:

$$
w_{t}=(1-\alpha)\left(\frac{\alpha}{R}\right)^{\frac{\alpha}{1-\alpha}} A_{t}
$$

Note that during the transition, wages per effective unit of labor, $w_{t} / A_{t}$, are constant due to a constant rental rate for capital and, accordingly, a constant capital-to-labor ratio, $\left(k_{t}^{F} / A_{t} n_{t}^{F}\right)=(\alpha / R)^{\frac{1}{1-\alpha}}$.

\subsection{The E-firm's problem}

Following Song et al. (2011), we assume that E-firms must hire a manager (i.e. the young entrepreneur) and pay him a fixed $\psi<1$ fraction of the output produced as a compensation $m_{t}$, in order to satisfy an incentive-compatibility constraint. ${ }^{14}$ The incentive constraint is important, because in its absence managers would be paid the

\footnotetext{
${ }^{14}$ The managerial compensation must also exceed the workers' wage rate, i.e. $m_{t}>w_{t}$. We restrict attention to parameters and initial conditions such that the participation constraint is never binding in equilibrium.
} 
workers' wage, and the equilibrium would feature no capital accumulation in E-firms and no transition from F-firms to E-firms. In addition, under an active tax policy, the E-firm, owned by an old entrepreneur, must pay a tax $\tau$. Since, in reality, tax policies affect the overall profitability of private firms, we assume that such a policy also applies to young entrepreneurs' managerial compensation. Accordingly, the lump-sum transfer to workers $T_{t}$ is given by $T_{t}=\tau\left(k_{t}^{E}\right)^{\alpha}\left(A_{t} \chi n_{t}^{E}\right)^{1-\alpha}$. The old entrepreneur's problem can be written as:

$$
\max _{m_{t}, n_{t}^{E}}(1-\tau)\left(k_{t}^{E}\right)^{\alpha}\left(A_{t} \chi n_{t}^{E}\right)^{1-\alpha}-m_{t}-w_{t} n_{t}^{E}
$$

subject to the incentive constraint that $m_{t} \geq(1-\tau) \psi\left(k_{t}^{E}\right)^{\alpha}\left(A_{t} \chi n_{t}^{E}\right)^{1-\alpha}$, and arbitrage in the labor market implies that the wage is as in (1). The optimal contract implies that the incentive constraint is binding:

$$
m_{t}=(1-\tau) \psi\left(k_{t}^{E}\right)^{\alpha}\left(A_{t} \chi n_{t}^{E}\right)^{1-\alpha}
$$

Taking the first-order condition with respect to $n_{t}^{E}$ and substituting in the equilibrium wage yield optimal level of employment as:

$$
n_{t}^{E}=[(1-\tau)(1-\psi) \chi]^{\frac{1}{\alpha}}\left(\frac{R}{\alpha}\right)^{\frac{1}{1-\alpha}} \frac{k_{t}^{E}}{A_{t} \chi}
$$

Plugging Equations (4) and (3) into Equation (2) yields the value of the firm:

$$
\pi\left(k_{t}^{E}\right)=[(1-\tau)(1-\psi)]^{\frac{1}{\alpha}} \chi^{\frac{1-\alpha}{\alpha}} R k_{t}^{E} \equiv \rho_{t}^{E} k_{t}^{E}
$$

where $\rho^{E}$ is the E-firm rate of return to capital. Following Song et al. (2011), we impose the following assumption about E-firms' relative productivity, such that an entrepreneur's return to capital is higher than the deposit rate, $R$, during the transition. 
Assumption 1: $\chi>[(1-\tau)(1-\psi)]^{-\frac{1}{1-\alpha}}$

Given this assumption, young entrepreneurs would find it optimal to invest in the family business. If Assumption 1 were not satisfied, there would be no E-firms in equilibrium. Thus, a sufficiently large productivity difference is necessary to trigger economic transition.

\subsection{The young entrepreneur's problem}

As in Chen and Wen (2017), the young entrepreneur decides on consumption and portfolio allocations in housing investment, bank deposits, or physical capital investment. The rate of return to capital investment is simply $\rho_{t}^{E}$. We assume that the balanced growth rate, which equals the rate of return to housing investment at the steady state, is greater than the bank deposit rate - that is, $(1+z)(1+v)>R$. As a result, the entrepreneur will always prefer investing in housing to depositing funds in the bank. Given housing prices, $P_{t}^{H}$, the young entrepreneur faces a two-stage problem.

In the first stage, a young entrepreneur's consumption-saving problem is:

$$
\max _{s_{t}^{E}} \log \left(m_{t}-s_{t}^{E}\right)+\beta \log R_{t+1}^{E} s_{t}^{E}
$$

where $R_{t+1}^{E} \equiv \max \left\{\rho^{E}, P_{t+1}^{H} / P_{t}^{H}\right\}$ is the rate of return for the entrepreneur's savings and depends on the entrepreneur's portfolio choices. First-order conditions give the optimal savings of the young entrepreneur as $s_{t}^{E}=\frac{m_{t}}{\left(1+\beta^{-1}\right)}$.

In the second stage, the young entrepreneur chooses portfolio allocations, given total savings, $s_{t}^{E}$. The fraction $\phi_{t}^{E}$ of savings is invested in capital, such that $K_{t+1}^{E}=$ $\phi_{t}^{E} s_{t}^{E} N_{t}^{E}$, where $K_{t+1}^{E}=k_{t+1}^{E} N_{t+1}^{E}$ is total E-firm capital. The remaining $\left(1-\phi_{t}^{E}\right)$ fraction of savings is invested in housing, such that $P_{t}^{H} H_{t}^{E}=\left(1-\phi_{t}^{E}\right) s_{t}^{E} N_{t}^{E}$, where $H_{t}^{E}$ is the total housing stock purchased by young entrepreneurs in period $t$. In addition, 
we ensure that there exists an interior solution for the portfolio choice, such that the following no-arbitrage condition holds:

$$
\frac{P_{t+1}^{H}}{P_{t}^{H}}=\rho_{t+1}^{E}
$$

where $\rho_{t+1}^{E}=\rho^{E}$ is constant during the transition. Therefore, an old entrepreneur's income is simply $\rho^{E} s_{t}^{E}$. The above condition states that the entrepreneur's rate of return to housing and rate of return to capital must be equal in a bubbly equilibrium. That is, the young entrepreneur is indifferent between investing in the capital stock or in the housing asset. In addition, we assume that for each period the bank simply absorbs deposits from young workers, lends out to F-firms at interest rate $R$, and then invests the rest in foreign bonds with the same rate of return $R$, as in Song et al. (2011).

\subsection{Law of motion}

We now characterize the equilibrium dynamics during a transition in which there is positive employment in both E- and F-firms. There are two state variables in this model: $K_{t}^{E}$ and $A_{t}$. Since the E-firm is self-financed, the law of motion for E-firm capital stock follows:

$$
K_{t+1}^{E}=\phi_{t}^{E} \frac{\rho_{t}^{E} \psi}{(1-\psi) \alpha} \frac{1}{1+\beta^{-1}} K_{t}^{E}
$$

where $\rho_{t}^{E}=[(1-\tau)(1-\psi)]^{\frac{1}{\alpha}} \chi^{\frac{1-\alpha}{\alpha}} R$ for all periods during the transition stage. The entrepreneur's portfolio share in physical capital, $\phi_{t}^{E}$, is constant, as shown later, which together with a constant $\rho^{E}$, implies that the growth rate of E-firm capital is constant during the transition. Similarly, the law of motion for housing demand is:

$$
P_{t}^{H} \bar{H}=\left(1-\phi_{t}^{E}\right) \frac{\rho_{t}^{E} \psi}{(1-\psi) \alpha} \frac{1}{1+\beta^{-1}} K_{t}^{E}
$$


where we have used the housing market-clearing condition, $H_{t}^{E}=\bar{H}$. Here, we assume that the housing supply is fixed, which reflects the fact that land available for home construction in China is strictly controlled by the government. ${ }^{15}$

\subsection{Post-transition equilibrium and the steady state}

Once the transition is completed, F-firms disappear and all workers are employed by E-firms. Thereafter, the theory predicts standard OLG-model dynamics. Since $n_{t}^{E}=1$, E-firm profit is:

$$
\pi\left(k_{t}^{E}\right)=\alpha(1-\tau)(1-\psi)\left(k_{t}^{E}\right)^{\alpha}\left(A_{t} \chi\right)^{1-\alpha}
$$

and the rate of return to E-firm capital is simply $\rho_{t}^{E}=\alpha(1-\tau)(1-\psi)\left(k_{t}^{E}\right)^{\alpha-1}\left(A_{t} \chi\right)^{1-\alpha}$.

The steady state of the economy is reached only in the post-transition stage. Since all per capita variables (except labor inputs and housing) grow at the rate $A_{t}$, we detrend them as $\hat{x}_{t}=x_{t} / A_{t}$. At the steady state, the law of motion for capital (5) implies:

$$
\hat{k}^{E *}=\left[\frac{\psi \phi^{E *}(1-\tau) \chi^{1-\alpha}}{\left(1+\beta^{-1}\right)(1+z)(1+v)}\right]^{\frac{1}{1-\alpha}}
$$

Note that this equation shows the steady state capital $\hat{k}^{E *}$ is negatively related to the tax policy, $\tau$.

Given that $\rho^{E *}=\alpha(1-\tau)(1-\psi)\left(\hat{k}^{E *} / \chi\right)^{\alpha-1}$, we have

$$
\rho^{E *}=\alpha \frac{(1-\psi)}{\psi} \frac{\left(1+\beta^{-1}\right)(1+z)(1+v)}{\phi^{E *}}
$$

The equilibrium portfolio allocation $\phi^{E *}$ is solved by the no-arbitrage condition. Since the supply of housing is fixed, the growth rate of housing prices, denoted as

\footnotetext{
${ }^{15}$ According to the National Land Use Plan 2006-2020, passed by the State Council of China in 2008, the total land available for construction in urban and rural areas is limited to 506.25 million acres by 2010 and 558.6 million acres by 2020 .
} 
$\rho_{t+1}^{E}=P_{t+1}^{H} / P_{t}^{H}$, equals the balanced growth rate, $(1+z)(1+v)$, in the steady state. As a result, the no-arbitrage condition implies that the E-firm steady-state portfolio share in physical capital is:

$$
\phi^{E *}=\alpha(1-\psi)\left(1+\beta^{-1}\right) / \psi
$$

\subsection{Existence of bubbles and toxic bubbles}

We follow Chen and Wen (2017) and impose the parameter restrictions to ensure the existence of housing bubbles. Let us first consider the particular situation in which there is no equilibrium bubble - that is, all financial resources are invested in capital and none in housing, and $\phi_{t}^{E}=1$, for all $t$. This equilibrium is called the "fundamental equilibrium". ${ }^{16}$ Consider now the steady state case. For a housing bubble to exist in the fundamental equilibrium (i.e., $\phi^{E *}<1$ ), the rate of returns to E-firm capital, $\rho^{E *}$, must be below the balanced growth rate, $(1+z)(1+v)$. Intuitively, when the economy is dynamically inefficient from the perspective of the entrepreneurs, entrepreneurs would find it optimal to divert savings into housing as an alternative store of value. This condition requires, together with (9), the following assumption:

Assumption 2: $\psi>\alpha\left(1+\beta^{-1}\right) /\left[1+\alpha\left(1+\beta^{-1}\right)\right]$

This assumption implies that $\phi^{E *}<1$, that is, a housing bubble exists in the equilibrium. ${ }^{17}$ Alternatively, the same parameter restrictions can be achieved by setting $\phi^{E *}$ below one, using equation (10). The assumption also places a lower bound on $\psi$, as a larger $\psi$ makes the bubble more likely to emerge, either by reducing the entrepreneur's rate of return to E-firm capital or by increasing young entrepreneur's capital

\footnotetext{
${ }^{16}$ Note that the "fundamental equilibrium" always exists in our model and is important to be understood to characterize under what conditions a bubbly equilibrium can emerge.

${ }^{17}$ It is straightforward to show the same assumption can be used to ensure the existence of bubbles in the transition and post-transition stages, with the same reasoning. We omit this in order to save space.
} 
accumulation and thus lowering the marginal product of capital.

Note also that, in this model, due to agency frictions (i.e., $\psi>0$ ), there exists a wedge between the private and social rates of return of capital. Denote the social rate of return of E-firm capital as $M P K^{E}{ }^{18}$ we have $\rho^{E *}<M P K^{E}$. This implies, in contrast with the traditional bubble theory, a bubbly equilibrium may exist in the model under dynamic efficiency. ${ }^{19}$ This has dramatically different and important welfare implications from those in the traditional bubble literature, as we discuss below. For bubbles to exist when the economy is dynamically efficient, the steady state $M P K^{E}$ in the fundamental equilibrium should be larger than the balanced growth rate, which requires $\psi<\alpha\left(1+\beta^{-1}\right)$. This restriction, however, does not need to be imposed since Assumption 3 (shown below) is sufficient for this to hold.

Since bubbles can occur in our model with dynamic efficiency, owing to a disparity between social and private rates of return to capital, they may reduce, rather than increase, social welfare. Thus, by crowding out private capital formation and other productive activities, the growing bubble in our model crowds out productive investment, creates resource misallocation, prolongs economic transition, and reduces the resources available for aggregate consumption and social welfare. It is in this sense that housing bubbles are toxic. The following parameter restriction is imposed to ensure bubbles are welfare-reducing. ${ }^{20}$

\footnotetext{
${ }^{18}$ In the steady state, $M P K^{E}=\alpha\left(1+\beta^{-1}\right)(1+z)(1+v) / \psi \phi^{E *}$, this can be solved through a constrained optimization problem without agency frictions but with market imperfections as in the benchmark model.

${ }^{19}$ In the standard models of rational bubbles, the social and private returns to capital are assumed to be the same, and bubbles can occur only if the economy is dynamically inefficiency. As in Tirole (1985), when the economy is dynamically efficient, bubbles cannot exist and are ruled out by wealth constraints since growing bubbles would end up growing faster than the resources of the economy.

${ }^{20} \mathrm{It}$ is clear that, according to (8), introducing housing reduces the steady state physical capital. For housing bubbles to reduce aggregate consumption and welfare, it suffices to show under which condition a marginal reduction in capital reduces entrepreneurial consumption. Assumption 3 is the sufficient condition to ensure it. Once again, it is straightforward to carry over this to both the transition and post-transition stages.
} 
Assumption 3: $\psi<\alpha\left(1+\beta^{-1}\right)(1-\tau)[\psi+\alpha(1-\psi)]$

As shown above, if Assumption 2 and 3 are both satisfied, a housing bubble is toxic (welfare-reducing) in an environment with dynamic efficiency. ${ }^{21}$ Specifically, bubbles reduce aggregate consumption and the welfare of both entrepreneurs and workers. ${ }^{22}$ For entrepreneurs, in addition to foregone returns to capital, entrepreneurial housing investment reduces the lifetime income of future entrepreneurs and, thus, negatively impacts their consumption. For workers, in the post-transition stage, workers' lifetime utility decreases as a result of the housing bubble. This is because workers' wage income starts to depend positively on E-firm capital stock, while the rate of return to savings is still fixed. The feature that a housing bubble is toxic has important welfare implications and warrants government intervention, as we shall explore.

\section{Welfare analysis}

In this section, we study the welfare implications of an explicit government tax policy. Specifically, we first analyze the asymmetric effects of the tax policy on both entrepreneurs and workers. We then examine for the existence of an optimal tax rate at which welfare is maximized. In addition and more importantly, we compare social welfare with and without an active tax policy and explore the necessary conditions for which welfare is improved. Let us start with entrepreneur's welfare and worker's welfare at different stages.

Entrepreneur's (worker's) welfare, $u_{t}^{E}\left(u_{t}^{w}\right)$, is defined as entrepreneur's (worker's) lifetime utility, i.e., $u_{t}^{E}=\log c_{1 t}^{E}+\beta \log c_{2 t+1}^{E}$. In our OLG setup, agents are heterogenous by nature. Social welfare (defined below), $W_{t}$, is the sum of entrepreneur's and worker's

\footnotetext{
${ }^{21}$ It can be readily seen that since $\alpha<1$ and $(1-\tau)<1,(1-\tau)[\psi+\alpha(1-\psi)]<1$, Assumption 3 would imply $\psi<\alpha\left(1+\beta^{-1}\right)$, which is the restriction for bubbles to exist when the economy is dynamically efficient.

${ }^{22}$ Detailed welfare discussions are provided in the next section.
} 
welfare. It is the aggregate welfare of one generation born at period $t .^{23}$ Note that we keep tracking the agent's welfare over the lifespan, including their welfare when they are old. The tractability of our model allows us to analytically analyze agent's welfare at different stages of the economy, i.e., the transition stage, the post-transition stage, and the balanced growth equilibrium. Social welfare is studied, under the optimal tax policy, at the bubbly steady state in this section. ${ }^{24}$

Definition 1: Social welfare. Social welfare is defined as the sum of entrepreneur's and worker's lifetime utilities, which gives $W_{t}=u_{t}^{w}+u_{t}^{E}=\left(\log c_{1 t}^{w}+\beta \log c_{2 t+1}^{w}\right)+$ $\left(\log c_{1 t}^{E}+\beta \log c_{2 t+1}^{E}\right) \cdot{ }^{25}$

Lemma 1 summarizes the solutions to entrepreneur's welfare at the transition stage, the post-transition stage, and the steady state equilibrium. As discussed later, the welfare functions are also used to derive the optimal tax rate and explore the conditions under which an optimal policy is welfare-enhancing. All the proofs of lemmas and propositions are included in the Appendix.

Lemma 1 Given $\alpha, \beta, \chi, \psi, \tau$, and $k_{t}^{E}, A_{t}$, the entrepreneur's lifetime utility function can be expressed as:

1. For entrepreneurs born during the transition, the lifetime utility is:

$$
\begin{aligned}
& \log \left(m_{t}-s_{t}^{E}\right)+\beta \log \rho^{E} s_{t}^{E} \\
= & (1+\beta) \log \psi(1-\tau)^{\frac{1}{\alpha}}[(1-\psi) \chi]^{\frac{1-\alpha}{\alpha}}\left(\frac{R}{\alpha}\right) k_{t}^{E}+\beta \log [(1-\tau)(1-\psi)]^{\frac{1}{\alpha}} \chi^{\frac{1-\alpha}{\alpha}} R \\
& -\log (1+\beta)-\beta \log \left(1+\beta^{-1}\right)
\end{aligned}
$$

\footnotetext{
${ }^{23}$ Alternatively, we could define social welfare as the aggregate welfare of all generations who are alive at period $t$. This would include young entrepreneurs and workers born at period $t$ and old entrepreneurs and workers born at period $t-1$. Adopting this specification should not affect our analysis in any significant way. In addition, note that once the economy reaches the balanced growth path, consumption (after being detrended), and therefore welfare, would be the same for the generation born at $t$ and the generation born at $t+1$. Thus, it suffices to consider the aggregate welfare of one generation.

${ }^{24}$ In our quantitative exercise, we calibrate the model using Chinese data and study the implications of the tax policy in the transition stage.

${ }^{25}$ Note that we follow the assumption that workers and entrepreneurs are equally populated in the economy, as in Chen and Wen (2017).
} 
2. For entrepreneurs born in the post-transition stage, but before reaching the steady state, the lifetime utility is:

$$
\begin{aligned}
& \log \left(m_{t}-s_{t}^{E}\right)+\beta \log \rho_{t+1}^{E} s_{t}^{E} \\
= & \left(\alpha+\alpha^{2} \beta\right) \log k_{t}^{E}-(1-\alpha) \beta \log \phi_{t}^{E}+(1-\alpha)(1+\beta+\alpha \beta) \log A_{t} \chi \\
& +\log \frac{\psi(1-\tau)}{(1+\beta)}+\beta \log \frac{\alpha(1-\tau)^{1+\alpha}(1-\psi) \psi^{\alpha}(1+z)^{1-\alpha}}{\left(1+\beta^{-1}\right)^{\alpha}(1+v)^{\alpha-1}}
\end{aligned}
$$

3. For entrepreneurs born after reaching the steady state, the lifetime utility is (after being detrended):

$$
\begin{aligned}
& \log \left(\hat{m}^{*}-\hat{s}^{E *}\right)+\beta \log \rho^{E *} \hat{s}^{E *} \\
= & (1+\beta) \log \alpha \frac{(1-\psi)\left(1+\beta^{-1}\right)}{\psi}(1+z)(1+v)\left[\frac{\psi(1-\tau) \chi^{1-\alpha}}{\left(1+\beta^{-1}\right)(1+z)(1+v)}\right]^{\frac{1}{1-\alpha}} \\
& +\left[\frac{\alpha(1+\beta)}{1-\alpha}-\beta\right] \log \phi^{E *}+\log \left(\frac{\psi}{(1+\beta) \alpha(1-\psi)}\right)+\beta \log (1+v)
\end{aligned}
$$

Note that the rate of return to capital is constant during the transition period, whereas it starts to depend negatively on capital stock when the economy enters the post-transition period. In particular, $\rho^{E}$ is decreasing during the post-transition stage as capital accumulates; it is falling until the economy enters the steady state equilibrium.

Lemma 2 summarizes the solutions to worker's welfare at the transition stage, the post-transition stage, and the steady state equilibrium.

Lemma 2 Given $\alpha, \beta, \chi, \psi, \tau$, and $k_{t}^{E}, A_{t}$, the worker's lifetime utility function can be expressed as: 
1. For workers born during the transition, the lifetime utility is:

$$
\begin{aligned}
& \log \left(w_{t}-s_{t}^{w}+T_{t}\right)+\beta \log R s_{t}^{w} \\
= & (1+\beta) \log \left[(1-\alpha) A_{t}\left(\frac{\alpha}{R}\right)^{\frac{\alpha}{1-\alpha}}+\tau[(1-\tau)(1-\psi) \chi]^{\frac{1-\alpha}{\alpha}}\left(\frac{R}{\alpha}\right) k_{t}^{E}\right] \\
& +\log \frac{1}{1+\beta}+\beta \log \frac{R}{1+\beta^{-1}}
\end{aligned}
$$

2. For workers born in the post-transition stage, but before reaching the steady state, the lifetime utility is:

$$
\begin{aligned}
& \log \left(w_{t}-s_{t}^{w}+T_{t}\right)+\beta \log R s_{t}^{w} \\
= & (1+\beta) \log [(1-\tau)(1-\alpha)(1-\psi)+\tau \chi] A_{t}\left(k_{t}^{E}\right)^{\alpha}\left(A_{t} \chi\right)^{-\alpha} \\
& +\log \frac{1}{1+\beta}+\beta \log \frac{R}{1+\beta^{-1}}
\end{aligned}
$$

3. For workers born after reaching the steady state, the lifetime utility is (after being detrended):

$$
\begin{aligned}
& \log \left(\hat{w}^{*}-\hat{s}^{w *}+\hat{T}^{*}\right)+\beta \log R \hat{s}^{w *} \\
= & (1+\beta) \log [(1-\tau)(1-\alpha)(1-\psi)+\tau \chi]\left[\frac{\psi \phi^{E *}(1-\tau) \chi^{1-\alpha}}{\left(1+\beta^{-1}\right)(1+z)(1+v)}\right]^{\frac{\alpha}{1-\alpha}} \chi^{-\alpha} \\
& +\log \frac{1}{1+\beta}+\beta \log \frac{R}{1+\beta^{-1}}
\end{aligned}
$$

Note that the wage rate is constant during the transition when both E-firms and F-firms coexist. Unlike the rate of return to capital, the wage rate starts to depend positively on capital stock in the post-transition period. That is, it increases as E-firm's capital accumulates. Next, it is interesting to explore how such a tax policy affects the growth rate of housing prices at different stages of the economy.

Lemma 3 During both the transition and post-transition stages, the tax policy reduces housing bubbles.

In this model, the housing bubble arises because high capital returns driven by 
resource reallocation are not sustainable in the long run. Rational expectations of a strong future demand for alternative stores of value can thus induce currently productive agents to speculate in the housing market. During both the transition and post-transition stages, the growth rate of housing prices equals the rate of return of capital by no-arbitrage condition, i.e. $\frac{P_{t+1}^{H}}{P_{t}}=\rho_{t+1}^{E}$. Specifically, during the transition stage, $\rho^{E}$ is constant, $\rho^{E}=[(1-\tau)(1-\psi)]^{\frac{1}{\alpha}} \chi^{\frac{1-\alpha}{\alpha}} R$; during the post-transition stage, $\rho_{t}^{E}$ is a function of two state variables, $k_{t}^{E}$ and $A_{t}, \rho_{t}^{E}=\alpha(1-\tau)(1-\psi)\left(k_{t}^{E}\right)^{\alpha-1}\left(A_{t} \chi\right)^{1-\alpha}$. In either case, the housing growth rate is decreasing with a positive tax rate $\tau$. We now explore the welfare implications of such a tax policy.

Proposition 1 Given two state variables $k_{t}^{E}$ and $A_{t}$, during the transition and posttransition stages, entrepreneur's welfare is monotonically decreasing with the tax policy; however, worker's welfare is non-monotonically increasing with the tax policy. Specifically, in the transition stage, the welfare-maximizing optimal tax rate $\tau^{*}=\alpha$; in the post-transition stage, the welfare-maximizing optimal tax rate $\tau^{*}=\frac{\chi(1-\alpha)-\left(1-\alpha^{T+1}\right)(1-\alpha)(1-\psi)}{\chi\left(1-\alpha^{T+1}\right)-\left(1-\alpha^{T+1}\right)(1-\alpha)(1-\psi)}$, where $T \geq 1$ denotes the number of time periods since the economy enters the posttransition stage.

From Lemma 1, the entrepreneur's welfare is monotonically decreasing with a positive tax rate as the government directly tax both young and old entrepreneurs. For workers, although the welfare improvement with an active policy is positive, there exists a non-monotonic relationship between welfare and the tax rate. This is due to a trade-off effect of the tax policy. On the one hand, a positive tax rate increases workers' welfare as they receive real resources transferred for consumption every period. On the other hand, however, such a tax policy also implies a fall in capital accumulation, thus a decrease of productive resources. In the post-transition stage and steady state equilibrium, worker's wage rate is no longer constant and depends positively on the capital stock whereas their saving benefit is still fixed. Over time, the higher the tax 
rate, the lower real resources they can receive. Such a conflicting effect suggests that there may exist an optimal tax policy. We now turn to study the optimal policy which maximizes social welfare in the bubbly steady state.

Definition 2: Optimal tax policy. Our optimal tax policy is defined as a sequence of taxes $\left\{\tau_{t}\right\}$ set by the government at time $t=0$, which maximizes social welfare in the long-run balanced growth equilibrium. We assume the tax rate is constant over time, i.e., $\tau_{t}=\tau$.

That is, the objective of the planner is to find $\left\{\tau_{t}\right\}$ that produces a competitive equilibrium with taxes with highest utility for agents (entrepreneurs and workers) in the long-run equilibrium, subject to the fact that agents behave competitively for those taxes. ${ }^{26}$ Thus, by definition, our optimal tax policy is Ramsey-optimal. ${ }^{27}$ As is shown next, the tractability of the model allows us to find a closed-form solution to this problem.

Proposition 2 In the bubbly steady state, the worker's lifetime utility is nonmonotonically increasing with the tax policy. In particular, there exists an optimal tax rate $\tau^{*}=\frac{\chi(1-\alpha)-(1-\alpha)(1-\psi)}{\chi-(1-\alpha)(1-\psi)}$, at which worker's welfare is maximized. If we define social welfare as the sum of entrepreneur's and worker's lifetime utilities, then there exists an optimal tax rate $\tau^{* *}=\frac{\frac{1}{2} \chi(1-\alpha)-(1-\alpha)(1-\psi)}{\chi-(1-\alpha)(1-\psi)}$, at which welfare is maximized.

Let us focus on the welfare effects of an active tax policy in the bubbly steady state. Proposition 2 states that there exists an optimal tax rate for workers, because of the trade-off effect that we highlight above. In addition and more importantly, there exists

\footnotetext{
${ }^{26}$ This exercise is similar to the classic Barro (1990) in which he studies growth-maximizing and welfare-maximizing government tax policies. More recently, in a same spirit to ours, Ikeda and Phan (2016) study optimal taxation on bubble speculation where the government uses tax policy as a macroprudential tool to maximize expected utility in the stochastic bubble steady state.

${ }^{27}$ Note that, technically, several features of our model make the Ramsey problem easy to solve. First, agents have perfect foresight. Second, our social welfare function is simplified as we are concerned with one generation only. Third, in the detrended steady state, there is only one state variable $\hat{k}^{E *}$, all the other variables can be worked out analytically and expressed as functions of the policy $\tau$ and exogenous parameters.
} 
an optimum at which social welfare (the sum of entrepreneur's and worker's lifetime utilities) is maximized. This is still mainly because of the conflicting effect of tax policy on worker's welfare. However, the welfare losses of entrepreneurs have to be taken into consideration when it comes to the optimal tax rate for social welfare. Thus, one would expect a lower optimal tax, as discussed in Corollary 1.

Corollary 1 The size of the optimal tax rate for social welfare is smaller than that for worker's welfare: $\tau^{* *}<\tau^{*}$.

If we compare the two optimal tax rates, we find that the size of the optimal tax for social welfare is smaller than that for worker's welfare. This is because taking into account of the welfare losses of entrepreneurs makes one to compensate for them, thus requiring a lower value for the tax rate. This, however, does not affect the existence of an optimal tax rate.

\section{Assumption $4 \chi>2(1-\psi)$.}

From Proposition 2, the optimal tax rate of social welfare is given by $\tau^{* *}=$ $\frac{\frac{1}{2} \chi(1-\alpha)-(1-\alpha)(1-\psi)}{\chi-(1-\alpha)(1-\psi)}$. As the tax rate is positive, we have $\chi>2(1-\psi)$. Next, it would be interesting to explore whether and under what conditions that the optimal tax policy is welfare enhancing.

Proposition 3 In the bubbly steady state, setting the tax rate at the optimal level $\tau^{* *}=\frac{\frac{1}{2} \chi(1-\alpha)-(1-\alpha)(1-\psi)}{\chi-(1-\alpha)(1-\psi)}$ strictly improves worker's welfare by $(1+\beta) \log \left(\frac{\chi-\frac{1}{2} \chi(1-\alpha)}{\chi-(1-\alpha)(1-\psi)}\right)^{\frac{\alpha}{1-\alpha}} \frac{\frac{1}{2} \chi}{(1-\psi)}$, whereas such a tax policy strictly reduces entrepreneur's welfare by $(1+\beta) \log \left(\frac{\chi-\frac{1}{2} \chi(1-\alpha)}{\chi-(1-\alpha)(1-\psi)}\right)^{\frac{1}{1-\alpha}} \cdot{ }^{28}$

With agents having perfect foresight, if they anticipate that in each period the government implements the tax policy of combining an entrepreneurial tax and a lump-sum transfer to workers, they can evaluate the welfare effect of such a policy. Proposition 3 essentially states that, if the tax policy is implemented at its optimum, the worker's welfare is strictly improved by $(1+\beta) \log \left(\frac{\chi-\frac{1}{2} \chi(1-\alpha)}{\chi-(1-\alpha)(1-\psi)}\right)^{\frac{\alpha}{1-\alpha}} \frac{\frac{1}{2} \chi}{(1-\psi)}$, whereas the entrepre-

\footnotetext{
${ }^{28}$ Here we focus on the equilibrium with and without the optimal tax policy.
} 
neur's welfare is strictly reduced by $(1+\beta) \log \left(\frac{\chi-\frac{1}{2} \chi(1-\alpha)}{\chi-(1-\alpha)(1-\psi)}\right)^{\frac{1}{1-\alpha}}$. As such, if workers anticipate the effects of the tax policy, they would always prefer the tax rate to be set at the optimum.

Proposition 4 Compare to the equilibrium without the tax policy, setting the tax rate at the optimum $\tau^{* *}=\frac{\frac{1}{2} \chi(1-\alpha)-(1-\alpha)(1-\psi)}{\chi-(1-\alpha)(1-\psi)}$ improves social welfare, if $\left(\frac{\chi-\frac{1}{2} \chi(1-\alpha)}{\chi-(1-\alpha)(1-\psi)}\right)^{\frac{1+\alpha}{1-\alpha}} \frac{\frac{1}{2} \chi}{(1-\psi)}>$ 1. Compare to the equilibrium even without housing bubbles, setting the tax rate at the optimal level improves social welfare, if $\left(\frac{\chi-\frac{1}{2} \chi(1-\alpha)}{\chi-(1-\alpha)(1-\psi)}\right)^{\frac{1+\alpha}{1-\alpha}} \frac{\frac{1}{2} \chi}{(1-\psi)}\left(\phi^{E *}\right)^{\frac{2 \alpha}{1-\alpha}-\frac{\beta}{1+\beta}}>1$.

Proposition 4 states the condition under which an optimal tax policy is welfareenhancing, compare to the equilibrium without an active policy. The economic intuition is as follows. As mentioned above, housing bubbles are toxic (i.e. welfare-reducing) in this model as they reduce aggregate consumption and the welfare of both entrepreneurs and workers. For entrepreneurs, the tax policy is strictly welfare reducing. For workers, however, such a tax policy could compensate to some extent the welfare losses from a declining wage rate. In other words, an active tax policy makes the housing bubble less toxic to workers. If the benefits of workers dominate the costs of entrepreneurs, such a tax policy would improve social welfare. In addition, if the benefits from workers are large enough, it is possible that the optimal tax policy yields a higher level of social welfare than the case even without housing bubbles.

Numerical illustration. For illustrative purposes, we perform a numerical analysis based on realistic parameter values. ${ }^{29}$ This aims to give us a sense of how the model predictions are and how the qualitative results of the tax policy are sensitive to different parameter values. A more concrete calibration for the Chinese economy and thus quantitative analysis are provided in the next section. ${ }^{30}$

\footnotetext{
${ }^{29}$ Our parameter values follow those of Song et al. (2014), who calibrate a similar two-period OLG model for China, with each period corresponding to 30 calendar years. We set $\alpha=0.5, R=$ $(1.0175)^{30}, \beta=(0.98)^{30}, \psi=0.625, \chi=8.24, z=(1.038)^{30}-1, v=(1.03)^{30}-1$.

${ }^{30}$ For quantitative arguments, it is necessary to extend our benchmark model to a multi-period OLG setting.
} 
Figure 1 shows the relationship between social welfare at the bubbly steady state and the tax rate. ${ }^{31}$ It is clear that there is an inverted U-shaped curve where an optimal tax policy exists, thanks to the non-monotonic relation between worker's welfare and the policy rate. Following Proposition 2, we can calculate the optimal tax rate $\tau^{* *}=$ $23.25 \%$, at which social welfare is maximized. That is, the optimal tax policy requires the setting of a $23 \%$ tax on entrepreneurs with a one-time redistribution to workers. This policy would reduce entrepreneur's welfare while strictly improve worker's welfare, according to Proposition 3.

Proposition 4 suggests that if $\left(\frac{\chi-\frac{1}{2} \chi(1-\alpha)}{\chi-(1-\alpha)(1-\psi)}\right)^{\frac{1+\alpha}{1-\alpha}} \frac{\frac{1}{2} \chi}{(1-\psi)}>1$, setting an optimal tax is welfare-improving. Given our parameter values, our calculation indicates that, $\left(\frac{\chi-\frac{1}{2} \chi(1-\alpha)}{\chi-(1-\alpha)(1-\psi)}\right)^{\frac{1+\alpha}{1-\alpha}} \frac{1}{2} \chi \frac{1}{(1-\psi)}=4.9664$, and social welfare is improved by 1.0757 (or in relative term, 19.6\%). ${ }^{32}$ Specifically, in accordance to Proposition 3, having normalized the initial welfare value to be the same for the two groups, we find a large increase in the level of welfare for workers (by 1.431, or in relative term, 36.6\%), whereas the drop in entrepreneur's welfare is relatively moderate (by 0.3553, or in relative term, $22.3 \%$ ). In addition, we try to evaluate the welfare gains (or losses) with the optimal tax rate, compared to the case even without housing bubbles. Based on Proposition

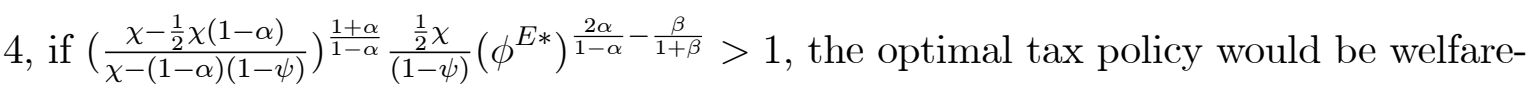
enhancing. We show that, $\left(\frac{\chi-\frac{1}{2} \chi(1-\alpha)}{\chi-(1-\alpha)(1-\psi)}\right)^{\frac{1+\alpha}{1-\alpha}} \frac{\frac{1}{2} \chi}{(1-\psi)}\left(\phi^{E *}\right)^{\frac{2 \alpha}{1-\alpha}-\frac{\beta}{1+\beta}}=3.80 \mathrm{in}$ this case, and social welfare is improved by 0.896 (or in relative term, 16.8\%). In sum, our simple numerical experiments indicate that, using realistic parameter values specific to Chinese economy, a government tax policy can yield a higher level of social welfare, compared to the case without active policies or even without housing bubbles. The relative gains are from workers (albeit small losses for entrepreneurs) for whom such an active tax

\footnotetext{
${ }^{31}$ For illustrative purposes, we set $\tau \in[0,0.5]$, for otherwise the tax burden would be too high.

${ }^{32}$ The relative welfare improvement might seem large as we are only doing the steady state analysis of a two-period OLG model.
} 
policy would compensate the welfare losses from toxic housing bubbles and a declining wage income.

Sensitivity analysis. We perform sensitivity analysis with regard to some key parameters. We are interested in evaluating two parameters, $\psi$ and $\chi$, as they are not explored in the literature despite having important policy implications on social welfare. $\psi$ reflects the managerial cost involved in managing private firms, while $\chi$ measures the productivity difference between E-firms and F-firms. Note that in our model, $\psi$ and $\chi$ are simultaneously solved for the capital-output ratio of the two types of firms and the rate of return of capital $\rho^{E}$. That is, (i) denote $\kappa_{F}, \kappa_{E}$ as capital to output ratio for F-firms and E-firms, given $\alpha, \kappa_{F} / \kappa_{E}=[(1-\psi) \chi]^{\frac{1-\alpha}{\alpha}}$; (ii) given $\alpha$ and $R$, $\rho^{E}=(1-\psi)^{\frac{1}{\alpha}} \chi^{\frac{1-\alpha}{\alpha}} R$. In general, F-firms (as state-owned enterprises) have a higher capital-to-output ratio, which means $\kappa_{F} / \kappa_{E}>1$, and $\rho^{E}$ is also greater than one. In this section, we first set $\chi$ at its benchmark value and perform sensitivity analysis with respect to $\psi$. Then, we set $\psi$ at its benchmark value and perform sensitivity analysis with respect to $\chi$. Results are shown in Table 1 and Table 2 , respectively.

In Table 1 , we vary the value of $\psi$ from 0.15 to $0.65,{ }^{33}$ while keeping $\chi$ constant at its benchmark, and we report also the optimal tax rate and welfare gains, compare to the case without such a tax policy. Our results show that as $\psi$ increases, the optimal tax rate decreases and so do the welfare gains. ${ }^{34}$ The optimal tax rate however does not change much, ranging from about $21 \%$ to $23 \%$. More importantly, we find that there are always welfare gains with an active tax policy. In other words, the lower the managerial cost involved, the more room the economy gains in terms of social welfare.

Similar results hold when we vary the value of $\chi$ from 7 to $12,{ }^{35}$ as shown in Table

\footnotetext{
${ }^{33} \mathrm{~A}$ value higher than 0.65 would yield a capital return rate $\rho^{E}$ that is smaller than 1 , which means the economy is not having a bubble. These scenarios are therefore not examined.

${ }^{34}$ It is immediately clear that both $\kappa_{F} / \kappa_{E}$ and $\rho^{E}$ are negatively related to $\psi$ and positively related to $\chi$.

${ }^{35} \mathrm{~A}$ value smaller than 7 would yield a capital return rate $\rho^{E}$ small than 1.
} 
2. Both the optimal tax rate and welfare are increased with a higher $\chi$, and the welfare gains are always positive in the range. In essence, it means the larger the initial productivity difference between the two types of firms, the higher the optimal tax rate, though this has no effect on the welfare-enhancing property of the one-off tax policy. The above experiments imply that, under the tax policy, the benefits for workers are generally large enough to compensate the losses of entrepreneurs, which in turn yields a higher level of social welfare.

Indeed, we also explore a case where workers are allowed to speculate in the housing market. This involves assuming the workers to put a fixed fraction of their savings, $\varrho$, in the housing market and receive the same housing returns as those of the entrepreneurs, $\rho_{t}^{E}$. In this instance, in the second period, on top of the interest return, $R$, workers receive also the housing returns, and therefore have second-period consumption as $c_{2 t+1}^{w}=s_{t}^{w}\left[(1-\varrho) R+\varrho \rho_{t}^{E}\right] \cdot{ }^{36}$ While it turns out that this specific case does not allow for the analytical derivation of a closed-form optimal tax rate as in Proposition 1, we verified that Propositions 2-4 remain largely true, such that, setting the tax rate at the optimal level $\tau^{* *}$ strictly improves social welfare in the bubbly steady state, despite the negative effect on housing speculations. ${ }^{37}$

\section{Quantitative analysis}

To closely match the theory with China's experience over the past two decades, a twoperiod OLG model, in which one period corresponds to 30 years, is inadequate. Thus, we extend our benchmark two-period model to a multi-period model. In the model, agents live for $J$ periods, are born with zero wealth, and cannot die with negative wealth. Worker supply one unit of labor each period. They retire after $J^{R}$ years of

\footnotetext{
${ }^{36}$ In fact, given that $\rho_{t}^{E}>R$, workers will always invest in housing up to $\varrho$ share of their savings.

${ }^{37}$ Derivations of this experiment are available upon request.
} 
work. Young entrepreneurs work for old entrepreneurs in the first $J^{E}$ periods of life. In the economy, we assume the capital depreciation rate $\delta<1$. In this section, we consider only the transition stage of the economy when both E-firms and F-firms coexist. ${ }^{38}$ The aim of this section is to explore the quantitative effects of active tax policies on the real economy.

\subsection{The multi-period model}

For a worker of age $i$ in period $q$, the problem for the remainder of her life is:

$$
\max \sum_{j=i}^{J} \beta^{j-i} \log c_{j, t}^{w}
$$

subject to

$$
\begin{gathered}
c_{j, t}^{w}+s_{j, t}^{w}=w_{t}+R s_{j-1, t-1}^{w}+T_{t}, j<J^{R} \\
c_{j, t}^{w}+s_{j, t}^{w}=R s_{j-1, t-1}^{w}, j \geq J^{R} \\
s_{J, t}^{w}=0, s_{0, t-1}^{w}=0
\end{gathered}
$$

where $t \equiv q+j-i$ is the calendar time for the age $i$ agent to become age $j$.

The F-firm's problem is similar to that in our benchmark model:

$$
\max _{k_{t}^{F}, n_{t}^{F}}\left(k_{t}^{F}\right)^{\alpha}\left(A_{t} n_{t}^{F}\right)^{1-\alpha}-w_{t} n_{t}^{F}-R^{l} k_{t}^{F}+(1-\delta) k_{t}^{F}
$$

To facilitate calibrations, we follow Chen and Wen (2017) and assume that lending to

\footnotetext{
${ }^{38}$ The long-run equilibrium has been thoroughly examined in the previous section.
} 
an F-firm is subject to a constant iceberg cost, $\xi$, which represents the intermediation cost. $^{39}$ In equilibrium, the lending rate for F-firms is $R^{l}=R /(1-\xi)$.

An age $j$ old entrepreneur in time $t$ solves the following problem:

$$
\max _{n_{j, t}^{E}}(1-\tau)(1-\psi)\left(k_{j, t}^{E}\right)^{\alpha}\left(A_{t} \chi n_{j, t}^{E}\right)^{1-\alpha}-w_{t} n_{j, t}^{E}+(1-\delta) k_{j, t}^{E}
$$

where $k_{j, t}^{E}$ and $n_{j, t}^{E}$ denote the capital and labor deployed by an age $j$ entrepreneur at period $t$.

An entrepreneur of age $i$ in period $q$ has the following consumption-saving problem:

$$
\max \sum_{j=i}^{J} \beta^{j-i} \log c_{j, t}^{E}
$$

subject to

$$
\begin{gathered}
c_{j, t}^{E}+s_{j, t}^{E}=m_{t}+R s_{j-1, t-1}^{E}, j<J^{E}-1 \\
c_{j, t}^{E}+s_{j, t}^{E}=\rho_{t}^{E} s_{j-1, t-1}^{E}, j \geq J^{E}-1 \\
s_{J, t}^{E} \geq 0, j \geq J^{E}-1 \\
s_{J, t}^{E}=0, s_{0, t-1}^{E}=0
\end{gathered}
$$

Here, for simplicity, we assume that an age $j\left(j<J^{E}-1\right)$ young entrepreneur can only make deposits in the bank with a fixed return, $R$. In addition, given savings, $s_{j, t}^{E}$, the age $j$ young entrepreneur at period $t$ makes the portfolio choice, $\phi_{j, t}^{E}$.

\footnotetext{
${ }^{39}$ Alternatively, $\xi$ can be interpreted as a measure of financial development, see Song et al. (2011) for a discussion.
} 
Finally, aggregate capital and housing stock in equilibrium follow the equations:

$$
\begin{gathered}
K_{t+1}^{E}=\phi_{t}^{E} \sum_{j=J^{E}-1}^{J-1} N_{j, t}^{E} s_{j, t}^{E} \\
P_{t}^{H} \bar{H}=\left(1-\phi_{t}^{E}\right) \sum_{j=J^{E}-1}^{J-1} N_{j, t}^{E} s_{j, t}^{E}
\end{gathered}
$$

where $N_{j, t}^{E}$ represents the number of age $j$ entrepreneurs at period $t$, and we have used the housing market-clearing condition, $H_{t}^{E}=\bar{H}$.

\subsection{Calibration}

The calibration of our multi-period model largely follows those of Chen and Wen (2017). We focus on the transition stage of the Chinese economy during 1998-2012, a period with high housing price and output growth, reallocation within the manufacturing sector, and sustained returns on capital. ${ }^{40}$ Each period in our model corresponds to one calendar year. Agents enter the economy at age 28 and live until $78(J=50)$. The average retirement age in China is 58 , so workers retire after $J^{R}=50$ years of work. Young entrepreneurs work as managers for $J / 2\left(J^{E}=25\right)$ periods and as entrepreneurs for the remaining periods.

In terms of technology parameters, the capital income share is set $\alpha=0.5$, consistent with Bai et al. (2006). The capital depreciation rate is set to $\delta=0.1$, which is the average depreciation rate between 1998 and 2012 (see Chen and Wen 2017). We assume an annualized world interest rate of 1.75 percent, following Song et al. (2011), that is, $R=1.0175$. The land supply is normalized to unity, $\bar{H}=1$. On the demand side, $\beta$ is calibrated to 0.994 so as to generate a 40 percent household savings rate (in the absence of activist policies), which meets the average urban household savings rate

\footnotetext{
${ }^{40}$ Note that China began to privatize its SOE in 1998.
} 
in 1998-2012 (Chen and Wen 2017). In addition, $\psi$ and $\chi$ are calibrated to match two empirical moments: (i) the capital-output ratio of Chinese F-firms is around 2.65 times larger than that of E-firms (average 1998-2005) (Song et al. 2011); (ii) the rate of return to capital is around 20 percent (Chen and Wen 2017). This yields $\psi=0.53$ and $\chi=5.64$. The iceberg cost $\xi$ is set to 0.00693 to target the 0.093 marginal product of capital for SOE. Finally, as in Chen and Wen (2017), the rate of labor-augmented technological growth is set to 3.8 percent, that is, $z=0.038$, to meet the average 10 percent growth rate of GDP during 1998-2012. The population growth rate is set to three percent, consistent with the average urban population growth rate in China during the same period, implying that $v=0.03$.

\subsection{Results}

Figure 2 shows the transitional dynamics of the calibrated multi-period economy when the tax policy is inactive. The calibrated model generates a high growth rate of housing prices, with an average growth rate of 19 percent between 2004 and 2011, consistent with the observed housing price patterns (see, e.g., Wu et al. 2012; 2014). ${ }^{41}$ Private employment share, by construction, increases during the transition. It features a reallocation from less efficient $\mathrm{F}$ firms to more efficient $\mathrm{E}$ firms (panel B). By 2010, the private employment share increases to around 63 percent, in line with statistics from the China Statistical Yearbook (see Chen and Wen 2017). Panel C of Figure 2 shows the aggregate rate of return to capital is persistently high between 1998 and 2012 . Given that the rate of return to capital is constant over time for both types of firms, and higher in private firms, the average return on capital increases steadily. Panel D of Figure 2 shows that the aggregate output growth in our calibrated economy satisfac-

\footnotetext{
${ }^{41}$ We chose the year 2004 as the starting point for housing prices because reliable housing price data are typically not available before 2004 (see, e.g., Wu et al. 2014; Fang et al. 2015).
} 
torily replicates China's GDP growth, with a 10 percent average growth rate between 1998 and 2012.

We now explore the quantitative effects of an active tax policy on the real economy by setting $\tau=0.2{ }^{42}$ Figure 3 plots the transition path for both the "active tax" and original economies. Panel A shows that with an active tax policy, the growth rate of housing prices is reduced. For example, the average growth rate between 2004 and 2011 is 11 percent, which is 8 percent lower than in the benchmark model. Panel B shows that the private employment share rises to around 75 percent by 2011, which is 8 percent larger than in the original economy. This in turn implies that the tax policy speeds up the economic transition by making housing bubbles less toxic. With growing labor reallocation from F-firms (unproductive firms) to E-firms (productive firms), resource misallocation is mitigated and higher output growth prevails (panel C). Panel $\mathrm{C}$ shows that aggregate output grows faster under an active tax policy, with a 10.5 percent average growth rate during 1998-2012. Panel D shows that aggregate consumption is higher with the tax policy. Between 1998 and 2012, aggregate consumption is 4.86 percent lower in the benchmark economy. ${ }^{43}$ In summary, our quantitative exercise shows that an active tax policy can mitigate the negative effects of toxic housing bubbles, accelerate economic transition, increase output growth, and generate higher aggregate consumption.

\footnotetext{
${ }^{42}$ Note that a closed-form solution of the welfare maximization problem cannot be obtained for our multi-period model. We have chosen $\tau=0.2$ for illustration, which is close to the optimal tax rate in the previous section.

${ }^{43}$ Note that since the tax revenue is transferred in a lump-sum fashion to young workers for consumption, worker's consumption unambiguously increases whereas entrepreneur's consumption falls under an active policy. In our quantitative experiment, the gains for workers outweigh the losses for entrepreneurs, therefore aggregate consumption increases.
} 


\section{Concluding remarks}

Housing prices have soared in Chinese cities over the last decades, which raises growing concerns across the world regarding the housing bubbles. Based on a growth model with economic transition and toxic housing bubbles applied to China, this paper designs and studies the welfare implications of an active government tax policy designed to curb housing bubbles. Such a policy combines taxing entrepreneurs with a one-time redistribution to workers in the same period. The aim of the study is to explore whether and how this tax policy can reduce the negative effects of a bubble and improve social welfare.

Under the tax policy, we find that the welfare improvement for workers is nonmonotonic. In particular, there exists an optimal tax rate at which worker's welfare is maximized. Defining social welfare as the sum of entrepreneur's and worker's lifetime utilities, we also find a closed-form tax at which social welfare is maximized. Moreover, we consider the welfare effects of setting the tax at its optimum. We show that the tax policy can be welfare-enhancing, compared to the case without active policies. The optimal tax may also yield a higher level of welfare than the case even without housing bubbles. In addition, our simple numerical exercise shows that the optimal tax rate is about 23 percent, and social welfare is significantly improved with such a tax policy. Finally, we calibrate the model to China and explore the quantitative effects of active tax policies on the real economy. Our results show that a 20 percent tax rate can speed up economic transition and increase output growth. Between 1998 and 2012, aggregate consumption is 4.86 percent higher under active tax policies. To the best of our knowledge, our paper is the first to investigate the impact of government policies on reducing the negative effects of housing bubbles and improving social welfare in a model environment with Chinese characteristics. 
It is also worth highlighting some directions in which our analysis can be extended. For tractability, the model has focused only on the demand side of housing market, and in particular, speculative motives. It however ignores the power of supply factors over housing prices. Physical construction costs and the price of land may have significant influence on shaping housing prices (Glaeser 2013). According to Glaeser et al. (2017), supply remains elastic in many Chinese cities, especially outside the first tier cities. Thus, a complete account for both demand and supply factors may improve our understandings of the great real estate boom in China. In addition, our paper considers only a simple tax policy. For future research, however, it would be interesting to analyze other types of government policies which are actively used in numerous countries, such as regulation on speculation (Hirano and Yanagawa 2017), loan-to-value (LTV) policy (Miao et al. 2015), home-purchase restriction (Du and Zhang 2015), leverage and collateral restriction (Zhao 2015; Ikeda and Phan 2016), and capital-subsidization policy (Dong et al. 2019a). These are all important issues for our future research. 


\section{References}

Azariadis, Costas, and Bruce D. Smith. 1993. "Adverse Selection in the Overlapping Generations Model: The Case of Pure Exchange." Journal of Economic Theory 60: 277-305.

Bai, Chong-En, Chang-Tai Hsieh, and Yingyi Qian. 2006. "The Return to Capital in China." Brookings Papers on Economic Activity 36: 61-88.

Barro, Robert J. 1990. "Government spending in a simple model of endogeneous growth." Journal of Political Economy 98: 103-125.

Caballero, Ricardo J., and Krishnamurthy, Arvind. 2006. "Bubbles and Capital Flow Volatility: Causes and Risk Management." Journal of Monetary Economics 53: 3553.

Chang, Chun, Kaiji Chen, Daniel F. Waggoner, and Tao Zha. 2015. "Trends and Cycles in China's Macroeconomy." NBER Working Paper No. 21244.

Chen, Jie, Mingzhi Hu, and Zhenguo Lin. 2019. "Does Housing Unaffordability Crowd Out Elites in Chinese Superstar Cities?" Journal of Housing Economics 45: 101571.

Chen, Ting, Laura Xiaolei Liu, Wei Xiong, and Li-An Zhou. 2017. "The Crowding-Out Effects of Real Estate Shocks - Evidence from China." Working paper.

Chen, Kaiji, and Yi Wen. 2017. "The Great Housing Boom of China." American Economic Journal: Macroeconomics 9: 73-114.

Dong, Feng, Yumei Guo, Yuchao Peng, and Zhiwei Xu. 2019a. "Economic Slowdown and Housing Dynamics in China: A Tale of Two Investments by Firms." Working paper.

Dong, Feng, Jianfeng Liu, Zhiwei Xu, and Bo Zhao. 2019b. "Flight to Housing like China." Working paper.

Dong, Feng, Jianjun Miao, and Pengfei Wang. 2018. "The Perils of Credit Booms." Economic Theory 66: 819-861.

Dong, Feng, Jianjun Miao, and Pengfei Wang. 2020. "Asset Bubbles and Monetary Policy." Review of Economic Dynamics, Forthcoming.

Dong, Feng, and Zhiwei Xu. 2019. "Bubbly Bailout." Working paper.

Dong, Feng, Zhiwei Xu, and Yu Zhang. 2019c. "Bubbly Bitcoin." Working paper.

Du, Zaichao, and Lin Zhang. 2015. "Home-purchase Restriction, Property Tax and Housing Price in China: A Counterfactual Analysis." Journal of Econometrics 188: 558-568.

Fang, Hanming, Quanlin Gu, Wei Xiong, and Li-An Zhou. 2015. "Demystifying the Chinese Housing Boom." In NBER Macroeconomic Annual 2015, Vol. 30, edited by Martin Eichenbaum and Jonathan Parker, 105-66. Chicago: University of Chicago Press.

Farhi, Emmanuel, and Jean Tirole. 2012. "Bubbly Liquidity." Review of Economic Studies 79: 678-706.

Galí, Jordi. 2014. "Monetary Policy and Rational Asset Price Bubbles." American Economic Review 104: 721-752.

Garriga, Carlos, Aaron Hedlund, Yang Tang, and Ping Wang. 2017. "Rural-Urban Migration, Structural Transformation, and Housing Markets in China." NBER Working 
Paper No. 23819.

Glaeser, Edward. 2013. "A Nation of Gamblers: Real Estate Speculation and American History." American Economic Review 103: 1-42.

Glaeser, Edward, Wei Huang, Yueran Ma, and Andrei Shleifer. 2017. "A Real Estate Boom with Chinese Characteristics." Journal of Economic Perspectives 31: 93-116.

Grossman, Gene, and Noriyuki Yanagawa. 1993. "Asset Bubbles and Endogenous Growth." Journal of Monetary Economics 31: 3-19.

Hellwig, Christian, and Lorenzoni, Guido. 2009. "Bubbles and Self-enforcing Debt." Econometrica 77: 1137-1164.

Hirano, Tomohiro, and Noriyuki Yanagawa. 2017. "Asset Bubbles, Endogenous Growth and Financial Frictions." Review of Economic Studies 84: 406-443.

Huang, Daisy J., Charles K. Leung, and Baozhi Qu. 2015. "Do Bank Loans and Local Amenities Explain Chinese Urban House Prices?" China Economic Review 34: 19-38.

Ikeda, Daisuke, and Toan Phan. 2016. "Toxic Asset Bubbles." Economic Theory 61: 241-271.

Kocherlakota, Narayana. 1992. "Bubbles and Constraints on Debt Accumulation." Journal of Economic Theory 57: 245-256.

Kocherlakota, Narayana. 2008. "Injecting Rational Bubbles." Journal of Economic Theory 142: 218-232.

Kocherlakota, Narayana. 2009. "Bursting Bubbles: Consequences and Cures." Working paper.

Martin, Alberto, and Jaume Ventura. 2012. "Economic Growth with Bubbles." American Economic Review 102: 3033-3058.

Miao, Jianjun. 2014. "Introduction to Economic Theory of Bubbles." Journal of Mathematical Economics 53: 130-136.

Miao, Jianjun, Zhouxiang Shen, and Pengfei Wang. 2020. "Monetary Policy and Rational Asset Price Bubbles: Comments." American Economic Review, Forthcoming.

Miao, Jianjun, and Pengfei Wang. 2012. "Bubbles and Total Factor Productivity." American Economic Review Papers and Proceedings 102: 82-87.

Miao, Jianjun, and Pengfei Wang. 2014. "Sectoral Bubbles, Misallocation, and Endogenous Growth." Journal of Mathematical Economics 53: 153-163.

Miao, Jianjun, and Pengfei Wang. 2015. "Banking Bubbles and Financial Crises." Journal of Economic Theory 157: 763-792.

Miao, Jianjun, and Pengfei Wang. 2018. "Asset Bubbles and Credit Constraints." American Economic Review 108: 2590-2628.

Miao, Jianjun, Pengfei Wang, and Lifang Xu. 2016. "Stock Market Bubbles and Unemployment." Economic Theory 61: 273-307.

Miao, Jianjun, Pengfei Wang, and Zhiwei Xu. 2015a. "A Bayesian DSGE Model of Stock Market Bubbles and Business Cycles." Quantitative Economics 6: 599-635.

Miao, Jianjun, Pengfei Wang, and Jing Zhou. 2015b. "Asset bubbles, Collateral and Policy Analysis." Journal of Monetary Economics 76: S57-S70.

Samuelson, Paul A. 1958. "An Exact Consumption-loan Model of Interest with or without the Social Contrivance of Money." Journal of Political Economy 66: 467-482. 
Santos, Manuel, and Michael Woodford. 1997. "Rational Asset Pricing Bubbles." Econometrica 65: 19-58.

Song, Zheng, Kjetil Storesletten, and Fabrizio Zilibotti. 2011. "Growing Like China." American Economic Review 101: 196-233.

Song, Zheng, Kjetil Storesletten, and Fabrizio Zilibotti. 2014. "Growing (with Capital Controls) Like China." IMF Economic Review 62: 327-370.

Tirole, Jean. 1985. "Asset Bubbles and Overlapping Generations." Econometrica 53: 1499-1528.

Wang, Pengfei, and Yi Wen. 2012. "Speculative Bubbles and Financial Crises." American Economic Journal: Macroeconomics 4: 184-221.

Wang, Shing-Yi. 2011. "State Misallocation and Housing Prices: Theory and Evidence from China." American Economic Review 101: 2081-2107.

Wang, Zhi, and Qinghua Zhang. 2014. "Fundamental Factors in the Housing Markets of China." Journal of Housing Economics 25: 53-61.

Weil, Philippe. 1987. "Confidence and the Real Value of Money in an Overlapping Generations Economy." Quarterly Journal of Economics 102: 1-22.

Woodford, Michael. 1990. "Public Debt as Private Liquidity." American Economic Review 80: 382-388.

Wu, Jing, Yongheng Deng, and Hongyu Liu. 2014. "House Price Index Construction in the Nascent Housing Market: The Case of China." Journal of Real Estate Finance and Economics 48: 522-545.

Wu, Guiying Laura, Qu Feng, and Pei Li. 2015. "Does Local Governments' Budget Deficit Push Up Housing Prices in China?" China Economic Review 35: 183-196.

Wu, Jing, Joseph Gyourko, and Yongheng Deng. 2012. "Evaluating Conditions in Major Chinese Housing Markets." Regional Science and Urban Economics 42: 531-543.

Wu, Jing, Joseph Gyourko, and Yongheng Deng. 2016. "Evaluating the Risk of Chinese Housing Markets: What We Know and What We Need to Know." China Economic Review 39: 91-114.

Zhang, Fudong. 2016. "Inequality and Housing Prices." Working paper.

Zhang, Yu. 2017. "Liquidity Constraints, Transition Dynamics, and the Chinese Housing Return Premium." Working paper.

Zhao, Bo. 2015. "Rational Housing Bubble." Economic Theory 60: 141-201. 
Table 1

Sensitivity analysis with respect to $\psi$

\begin{tabular}{lcccc}
\hline \hline & $\kappa_{F} / \kappa_{E}$ & $\rho^{E}$ & optimal tax rate & welfare gains \\
\hline \hline$\psi$ & & & & \\
0.150 & 7.0040 & 6.0576 & 0.2092 & 0.5868 \\
0.250 & 6.1800 & 4.7161 & 0.2142 & 0.6579 \\
0.350 & 5.3560 & 3.5423 & 0.2192 & 0.7412 \\
0.450 & 4.5320 & 2.5362 & 0.2241 & 0.8407 \\
0.550 & 3.7080 & 1.6978 & 0.2289 & 0.9627 \\
0.625 (the benchmark) & 3.0900 & 1.1790 & 0.2325 & 1.0757 \\
0.650 & 2.8840 & 1.0271 & 0.2337 & 1.1189 \\
\hline \hline
\end{tabular}

Source: authors' calculations

Table 2

Sensitivity analysis with respect to $\chi$

\begin{tabular}{lcccc}
\hline \hline & $\kappa_{F} / \kappa_{E}$ & $\rho^{E}$ & optimal tax rate & welfare gains \\
\hline \hline$\chi$ & & & & \\
7.00 & 2.6250 & 1.0016 & 0.2294 & 0.9746 \\
8.00 & 3.0000 & 1.1447 & 0.2320 & 1.0573 \\
8.24 (the benchmark) & 3.0900 & 1.1790 & 0.2325 & 1.0757 \\
9.00 & 3.3750 & 1.2878 & 0.2340 & 1.1310 \\
10.00 & 3.7500 & 1.4309 & 0.2357 & 1.1974 \\
11.00 & 4.1250 & 1.5739 & 0.2370 & 1.2579 \\
12.00 & 4.5000 & 1.7170 & 0.2381 & 1.3134 \\
\hline \hline
\end{tabular}

Source: authors' calculations 
Figure 1

Social Welfare at the Bubbly Steady State and the Tax Policy

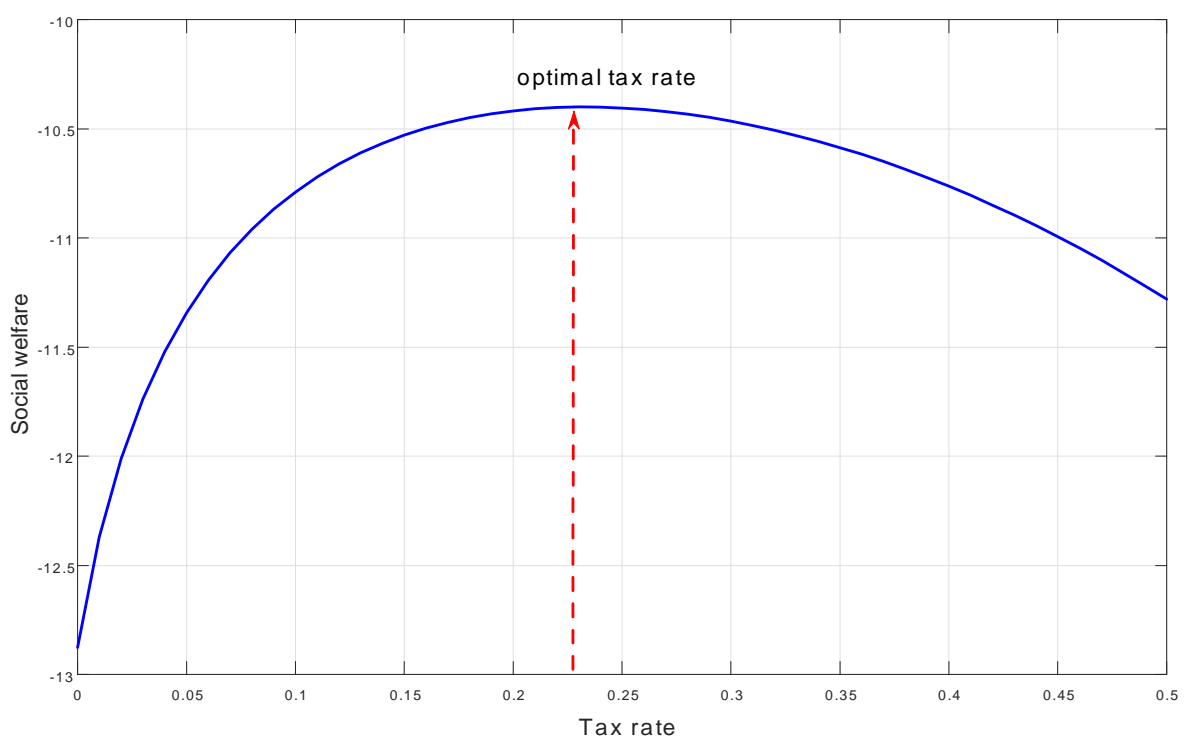


Figure 2

Transitional Dynamics in the Multi-period Calibrated Economy
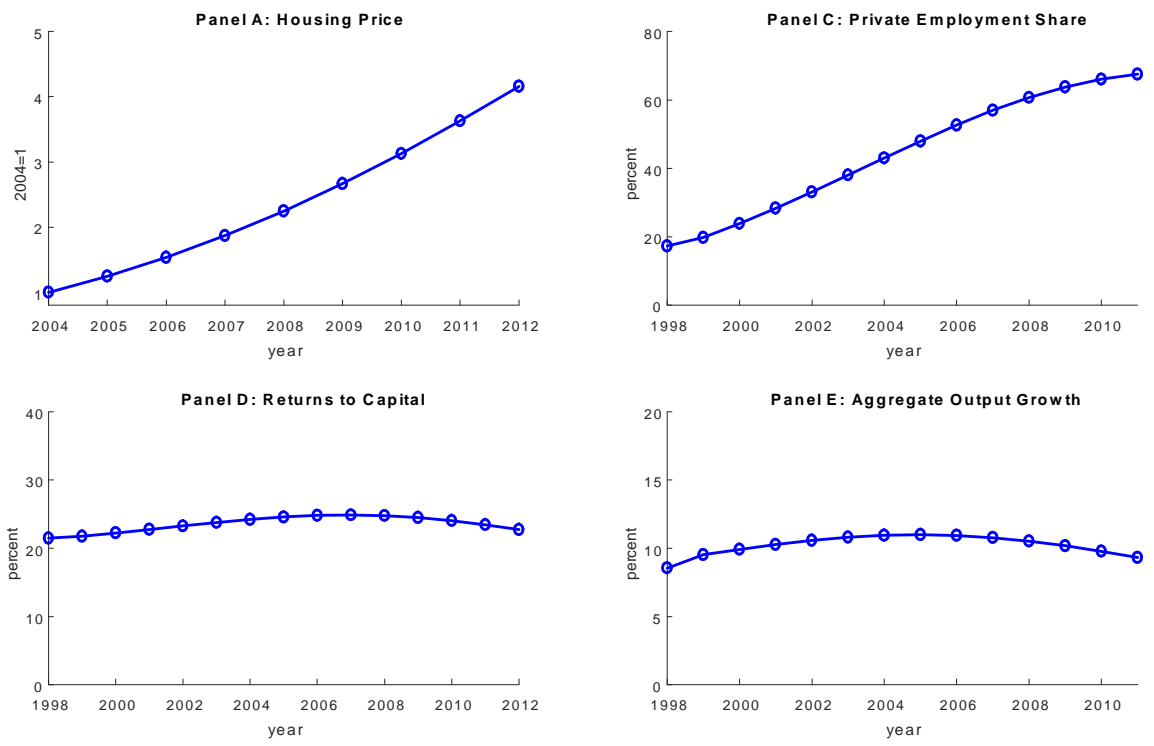
Figure 3

The Effects of Active Tax Policies in the Calibrated Economy
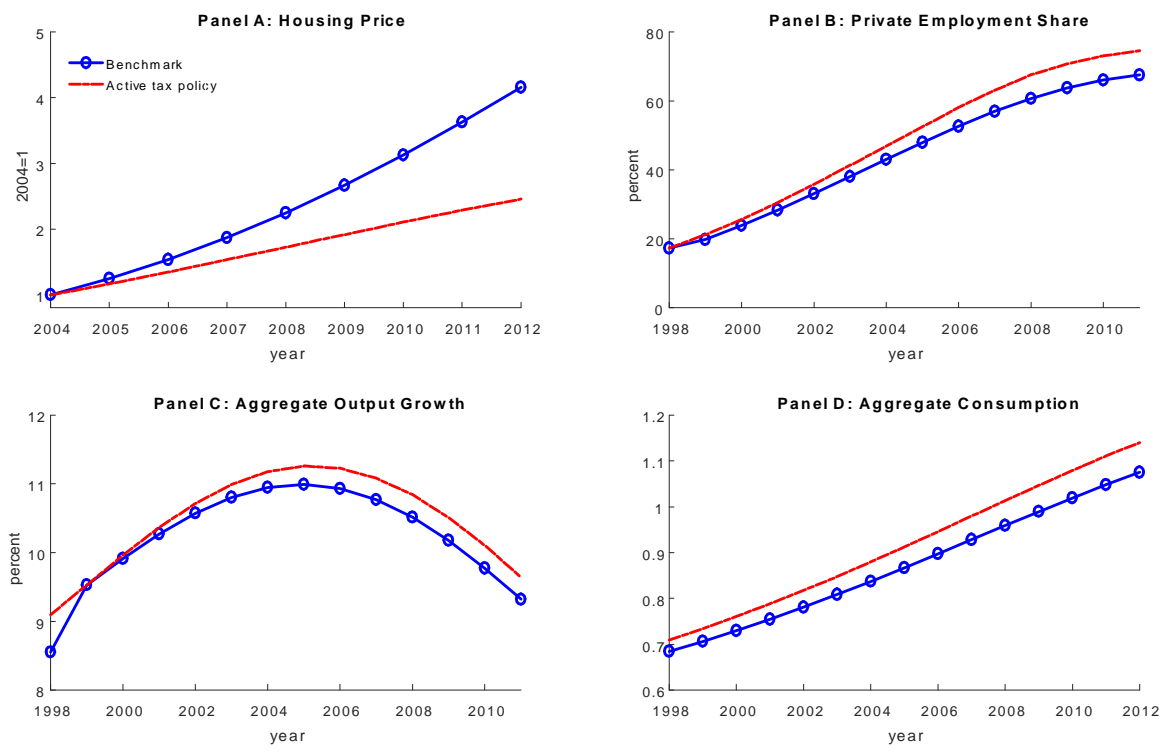


\section{Appendix: Proofs of Lemmas and Proposi- tions}

\section{Proof of Lemma 1}

For entrepreneurs born during the transition, the lifetime utility function is:

$$
\begin{aligned}
& \log \left(m_{t}-s_{t}^{E}\right)+\beta \log \rho^{E} s_{t}^{E} \\
= & \log \left(m_{t}-\frac{m_{t}}{1+\beta^{-1}}\right)+\beta \log \left(\frac{m_{t}}{1+\beta^{-1}}\right)+\beta \log \rho^{E} \\
= & (1+\beta) \log m_{t}+\beta \log \rho^{E}-\log (1+\beta)-\beta \log \left(1+\beta^{-1}\right) \\
= & (1+\beta) \log \psi(1-\tau)\left(k_{t}^{E}\right)^{\alpha}\left(A_{t} \chi n_{t}^{E}\right)^{1-\alpha}+\beta \log \rho^{E}-\log (1+\beta)-\beta \log \left(1+\beta^{-1}\right) \\
= & (1+\beta) \log \psi(1-\tau)^{\frac{1}{\alpha}}[(1-\psi) \chi]^{\frac{1-\alpha}{\alpha}}\left(\frac{R}{\alpha}\right) k_{t}^{E}+\beta \log [(1-\tau)(1-\psi)]^{\frac{1}{\alpha}} \chi^{\frac{1-\alpha}{\alpha}} R \\
& -\log (1+\beta)-\beta \log \left(1+\beta^{-1}\right)
\end{aligned}
$$

For entrepreneurs born in the post-transition stage, but before reaching the steady state, the lifetime utility function is:

$$
\begin{aligned}
& \log \left(m_{t}-s_{t}^{E}\right)+\beta \log \rho_{t+1}^{E} s_{t}^{E} \\
= & \log \left(\frac{\psi(1-\tau)\left(k_{t}^{E}\right)^{\alpha}\left(A_{t} \chi\right)^{1-\alpha}}{(1+\beta)}\right)+\beta \log \frac{\alpha(1-\tau)(1-\psi)\left(k_{t+1}^{E}\right)^{\alpha}\left(A_{t+1} \chi\right)^{1-\alpha}(1+v)}{\phi_{t}^{E}} \\
= & \log \left(\frac{\psi(1-\tau)\left(k_{t}^{E}\right)^{\alpha}\left(A_{t} \chi\right)^{1-\alpha}}{(1+\beta)}\right) \\
& +\beta \log \frac{\alpha(1-\tau)(1-\psi)\left[\frac{\phi_{t}^{E} \psi(1-\tau)\left(k_{t}^{E}\right)^{\alpha}\left(A_{t} \chi\right)^{1-\alpha}}{\left(1+\beta^{-1}\right)(1+v)}\right]^{\alpha}\left(A_{t}(1+z) \chi\right)^{1-\alpha}(1+v)}{\phi_{t}^{E}} \\
= & \log \left(\frac{\psi(1-\tau)\left(k_{t}^{E}\right)^{\alpha}\left(A_{t} \chi\right)^{1-\alpha}}{(1+\beta)}\right) \\
& +\beta \log \frac{\alpha(1-\tau)^{1+\alpha}(1-\psi) \psi^{\alpha}\left(\phi_{t}^{E}\right)^{\alpha-1}\left(k_{t}^{E}\right)^{\alpha^{2}}\left(A_{t} \chi\right)^{\alpha-\alpha^{2}}\left(A_{t}(1+z) \chi\right)^{1-\alpha}(1+v)}{\left[\left(1+\beta^{-1}\right)(1+v)\right]^{\alpha}} \\
= & \left(\alpha+\alpha^{2} \beta\right) \log k_{t}^{E}-(1-\alpha) \beta \log \phi_{t}^{E}+(1-\alpha)(1+\beta+\alpha \beta) \log A_{t} \chi \\
& +\log \frac{\psi(1-\tau)}{(1+\beta)}+\beta \log \frac{\alpha(1-\tau)^{1+\alpha}(1-\psi) \psi^{\alpha}(1+z)^{1-\alpha}}{\left(1+\beta^{-1}\right)^{\alpha}(1+v)^{\alpha-1}}
\end{aligned}
$$

For entrepreneurs born after reaching the steady state, the lifetime utility function is (after being detrended): 


$$
\begin{aligned}
& \log \left(\hat{m}^{*}-\hat{s}^{E *}\right)+\beta \log \rho^{E *} \hat{s}^{E *} \\
= & \log \left(\frac{\psi \rho^{E *} \hat{k}^{E *}}{(1+\beta) \alpha(1-\psi)}\right)+\beta \log \frac{\rho^{E *} \hat{k}^{E *}(1+v)}{\phi^{E *}} \\
= & (1+\beta) \log \rho^{E *} \hat{k}^{E *}-\beta \log \phi^{E *}+\log \left(\frac{\psi}{(1+\beta) \alpha(1-\psi)}\right)+\beta \log (1+v) \\
= & (1+\beta) \log \alpha \frac{(1-\psi)}{\psi} \frac{\left(1+\beta^{-1}\right)}{\phi^{E *}}(1+z)(1+v)\left[\frac{\psi \phi^{E *}(1-\tau) \chi^{1-\alpha}}{\left(1+\beta^{-1}\right)(1+z)(1+v)}\right]^{\frac{1}{1-\alpha}}-\beta \log \phi^{E *} \\
& +\log \left(\frac{\psi}{(1+\beta) \alpha(1-\psi)}\right)+\beta \log (1+v) \\
= & {\left[\frac{\alpha(1+\beta)}{1-\alpha}-\beta\right] \log \phi^{E *}+(1+\beta) \log \alpha \frac{(1-\psi)\left(1+\beta^{-1}\right)}{\psi}(1+z)(1+v)\left[\frac{\psi(1-\tau) \chi^{1-\alpha}}{\left(1+\beta^{-1}\right)(1+z)(1+v)}\right]^{\frac{1}{1-\alpha}} } \\
& +\log \left(\frac{\psi}{(1+\beta) \alpha(1-\psi)}\right)+\beta \log (1+v)
\end{aligned}
$$

\section{Proof of Lemma 2}

For workers born during the transition, the lifetime utility function is:

$$
\begin{aligned}
& \log \left(w_{t}-s_{t}^{w}+T_{t}\right)+\beta \log R s_{t}^{w} \\
= & \log \left(w_{t}-s_{t}^{w}+\tau\left(k_{t}^{E}\right)^{\alpha}\left(A_{t} \chi n_{t}^{E}\right)^{1-\alpha}\right)+\beta \log R s_{t}^{w} \\
= & \log \left(w_{t}-\zeta^{w}\left(w_{t}+\tau\left(k_{t}^{E}\right)^{\alpha}\left(A_{t} \chi n_{t}^{E}\right)^{1-\alpha}\right)+\tau[(1-\tau)(1-\psi) \chi]^{\frac{1-\alpha}{\alpha}}\left(\frac{R}{\alpha}\right) k_{t}^{E}\right) \\
& +\beta \log R \zeta^{w}\left(w_{t}+\tau\left(k_{t}^{E}\right)^{\alpha}\left(A_{t} \chi n_{t}^{E}\right)^{1-\alpha}\right) \\
= & \log \left[\frac{1}{1+\beta}(1-\alpha) A_{t}\left(\frac{\alpha}{R}\right)^{\frac{\alpha}{1-\alpha}}+\frac{1}{1+\beta} \tau[(1-\tau)(1-\psi) \chi]^{\frac{1-\alpha}{\alpha}}\left(\frac{R}{\alpha}\right) k_{t}^{E}\right] \\
& +\beta \log \frac{R}{1+\beta^{-1}}\left[(1-\alpha) A_{t}\left(\frac{\alpha}{R}\right)^{\frac{\alpha}{1-\alpha}}+\tau[(1-\tau)(1-\psi) \chi]^{\frac{1-\alpha}{\alpha}}\left(\frac{R}{\alpha}\right) k_{t}^{E}\right] \\
= & (1+\beta) \log \left[(1-\alpha) A_{t}\left(\frac{\alpha}{R}\right)^{\frac{\alpha}{1-\alpha}}+\tau[(1-\tau)(1-\psi) \chi]^{\frac{1-\alpha}{\alpha}}\left(\frac{R}{\alpha}\right) k_{t}^{E}\right] \\
& +\log \frac{1}{1+\beta}+\beta \log \frac{R}{1+\beta^{-1}}
\end{aligned}
$$

For workers born in the post-transition stage, but before reaching the steady state, the lifetime utility function is: 


$$
\begin{aligned}
& \log \left(w_{t}-s_{t}^{w}+T_{t}\right)+\beta \log R s_{t}^{w} \\
= & \log \left(w_{t}-s_{t}^{w}+\tau\left(k_{t}^{E}\right)^{\alpha}\left(A_{t} \chi\right)^{1-\alpha}\right)+\beta \log R s_{t}^{w} \\
= & \log \left(\frac{1}{1+\beta} w_{t}+\frac{1}{1+\beta} \tau\left(k_{t}^{E}\right)^{\alpha}\left(A_{t} \chi\right)^{1-\alpha}\right)+\beta \log \frac{R}{1+\beta^{-1}}\left(w_{t}+\tau\left(k_{t}^{E}\right)^{\alpha}\left(A_{t} \chi\right)^{1-\alpha}\right) \\
= & \log \left[\frac{1}{1+\beta} A_{t}(1-\tau)(1-\alpha)(1-\psi)\left(k_{t}^{E}\right)^{\alpha}\left(A_{t} \chi\right)^{-\alpha}+\frac{1}{1+\beta} \tau\left(k_{t}^{E}\right)^{\alpha}\left(A_{t} \chi\right)^{1-\alpha}\right] \\
& +\beta \log \frac{R}{1+\beta^{-1}}\left[A_{t}(1-\tau)(1-\alpha)(1-\psi)\left(k_{t}^{E}\right)^{\alpha}\left(A_{t} \chi\right)^{-\alpha}+\tau\left(k_{t}^{E}\right)^{\alpha}\left(A_{t} \chi\right)^{1-\alpha}\right] \\
= & (1+\beta) \log [(1-\tau)(1-\alpha)(1-\psi)+\tau \chi] A_{t}\left(k_{t}^{E}\right)^{\alpha}\left(A_{t} \chi\right)^{-\alpha} \\
& +\log \frac{1}{1+\beta}+\beta \log \frac{R}{1+\beta^{-1}}
\end{aligned}
$$

For workers born after reaching the steady state, the lifetime utility function is (after being detrended):

$$
\begin{aligned}
& \log \left(\hat{w}^{*}-\hat{s}^{w *}+\hat{T}^{*}\right)+\beta \log R \hat{s}^{w *} \\
= & \log \left(\hat{w}^{*}-\hat{s}^{w *}+\tau\left(\hat{k}^{E *}\right)^{\alpha} \chi^{1-\alpha}\right)+\beta \log R \hat{s}^{w *} \\
= & \log \left(\frac{1}{1+\beta} \hat{w}^{*}+\frac{1}{1+\beta} \tau\left(\hat{k}^{E *}\right)^{\alpha} \chi^{1-\alpha}\right)+\beta \log \frac{R}{1+\beta^{-1}}\left(\hat{w}^{*}+\tau\left(\hat{k}^{E *}\right)^{\alpha} \chi^{1-\alpha}\right) \\
= & \log \frac{1}{1+\beta}[(1-\tau)(1-\alpha)(1-\psi)+\tau \chi]\left(\hat{k}^{E *}\right)^{\alpha} \chi^{-\alpha} \\
& +\beta \log \frac{R}{1+\beta^{-1}}[(1-\tau)(1-\alpha)(1-\psi)+\tau \chi]\left(\hat{k}^{E *}\right)^{\alpha} \chi^{-\alpha} \\
= & (1+\beta) \log [(1-\tau)(1-\alpha)(1-\psi)+\tau \chi]\left[\frac{\psi \phi^{E *}(1-\tau) \chi^{1-\alpha}}{\left(1+\beta^{-1}\right)(1+z)(1+v)^{\frac{\alpha}{1-\alpha}} \chi^{-\alpha}}\right. \\
& +\log \frac{1}{1+\beta}+\beta \log \frac{R}{1+\beta^{-1}}
\end{aligned}
$$

\section{Proof of Lemma 3}

The housing bubble arises because high capital returns driven by resource reallocation are not sustainable in the long run. Rational expectations of a strong future demand for alternative stores of value can thus induce currently productive agents to speculate in the housing market. During both the transition and post-transition stages, the growth rate of housing prices equals the rate of return of capital by no-arbitrage condition, i.e. $\frac{P_{t+1}^{H}}{P_{t}}=\rho_{t+1}^{E}$. Specifically, during the transition stage, $\rho^{E}$ is constant, $\rho^{E}=[(1-\tau)(1-\psi)]^{\frac{1}{\alpha}} \chi^{\frac{1-\alpha}{\alpha}} R$; during the post-transition stage, $\rho_{t}^{E}$ is a function of two state variables, $k_{t}^{E}$ and $A_{t}$, $\rho_{t}^{E}=\alpha(1-\tau)(1-\psi)\left(k_{t}^{E}\right)^{\alpha-1}\left(A_{t} \chi\right)^{1-\alpha}$. In either case, the housing growth rate is decreasing with a positive tax rate $\tau$.

\section{Proof of Proposition 1}


From Lemma 1, it is obvious that during both the transition and posttransition stages, entrepreneur's welfare is monotonically decreasing with $\tau$. From Lemma 2, for workers born during the transition, the lifetime utility function is:

$$
\begin{aligned}
& \log \left(w_{t}-s_{t}^{w}+T_{t}\right)+\beta \log R s_{t}^{w} \\
= & (1+\beta) \log \left[(1-\alpha) A_{t}\left(\frac{\alpha}{R}\right)^{\frac{\alpha}{1-\alpha}}+\tau[(1-\tau)(1-\psi) \chi]^{\frac{1-\alpha}{\alpha}}\left(\frac{R}{\alpha}\right) k_{t}^{E}\right] \\
& +\log \frac{1}{1+\beta}+\beta \log \frac{R}{1+\beta^{-1}}
\end{aligned}
$$

By taking the first-order condition with respect to $\tau$, we find that the optimal tax rate is:

$$
\tau^{*}=\alpha
$$

For workers born in the post-transition stage, but before reaching the steady state, the lifetime utility function is:

$$
\begin{aligned}
& \log \left(w_{t}-s_{t}^{w}+T_{t}\right)+\beta \log R s_{t}^{w} \\
= & (1+\beta) \log [(1-\tau)(1-\alpha)(1-\psi)+\tau \chi] A_{t}\left(k_{t}^{E}\right)^{\alpha}\left(A_{t} \chi\right)^{-\alpha} \\
& +\log \frac{1}{1+\beta}+\beta \log \frac{R}{1+\beta^{-1}}
\end{aligned}
$$

Given the capital stock $k_{0}^{E}$ and technology level $A_{0}$ when the economy initially enters the post-transition stage, the worker's utility function can be rewritten as:

$$
\begin{aligned}
& \log \left(w_{t}-s_{t}^{w}+T_{t}\right)+\beta \log R s_{t}^{w} \\
= & (1+\beta) \log [(1-\tau)(1-\alpha)(1-\psi)+\tau \chi] \\
& +(1+\beta)\left(\frac{\alpha-\alpha^{T+1}}{1-\alpha}\right) \log (1-\tau)+\tilde{C}
\end{aligned}
$$

where $\tilde{C}$ is a function of parameters. By taking the first-order condition with respect to $\tau$, we find that the optimal tax rate is:

$$
\tau^{*}=\frac{\chi(1-\alpha)-\left(1-\alpha^{T+1}\right)(1-\alpha)(1-\psi)}{\chi\left(1-\alpha^{T+1}\right)-\left(1-\alpha^{T+1}\right)(1-\alpha)(1-\psi)}
$$

\section{Proof of Proposition 2}

From Lemma 2, for workers born after reaching the steady state, the lifetime utility function is (after being detrended): 


$$
\begin{aligned}
& \log \left(\hat{w}^{*}-\hat{s}^{w *}+\hat{T}^{*}\right)+\beta \log R \hat{s}^{w *} \\
= & (1+\beta) \log [(1-\tau)(1-\alpha)(1-\psi)+\tau \chi]\left[\frac{\psi \phi^{E *}(1-\tau) \chi^{1-\alpha}}{\left(1+\beta^{-1}\right)(1+z)(1+v)}\right]^{\frac{\alpha}{1-\alpha}} \chi^{-\alpha} \\
& +\log \frac{1}{1+\beta}+\beta \log \frac{R}{1+\beta^{-1}}
\end{aligned}
$$

By taking the first-order condition with respect to $\tau$, we find the optimal tax rate is:

$$
\tau^{*}=\frac{\chi(1-\alpha)-(1-\alpha)(1-\psi)}{\chi-(1-\alpha)(1-\psi)}
$$

The social welfare is:

$$
\begin{aligned}
W= & u^{w}+u^{E} \\
= & {\left[\log \left(\hat{w}^{*}-\hat{s}^{w *}+\hat{T}^{*}\right)+\beta \log R \hat{s}^{w *}\right]+\left[\log \left(\hat{m}^{*}-\hat{s}^{E *}\right)+\beta \log \rho^{E *} \hat{s}^{E *}\right] } \\
= & (1+\beta) \log [(1-\tau)(1-\alpha)(1-\psi)+\tau \chi]\left[\frac{\psi \phi^{E *}(1-\tau) \chi^{1-\alpha}}{\left(1+\beta^{-1}\right)(1+z)(1+v)}\right]^{\frac{\alpha}{1-\alpha}} \chi^{-\alpha} \\
& +(1+\beta) \log \alpha \frac{(1-\psi)\left(1+\beta^{-1}\right)}{\psi}(1+z)(1+v)\left[\frac{\psi(1-\tau) \chi^{1-\alpha}}{\left(1+\beta^{-1}\right)(1+z)(1+v)}\right]^{\frac{1}{1-\alpha}} \\
& +\log \frac{1}{1+\beta}+\beta \log \frac{R}{1+\beta^{-1}}+\left[\frac{\alpha(1+\beta)}{1-\alpha}-\beta\right] \log \phi^{E *} \\
& +\log \left(\frac{\psi}{(1+\beta) \alpha(1-\psi)}\right)+\beta \log (1+v)
\end{aligned}
$$

By taking the first-order condition with respect to $\tau$, we find the optimal tax rate is:

$$
\tau^{* *}=\frac{\frac{1}{2} \chi(1-\alpha)-(1-\alpha)(1-\psi)}{\chi-(1-\alpha)(1-\psi)}
$$

\section{Proof of Corollary 1}

$$
\begin{aligned}
\tau^{* *}-\tau^{*} & =\frac{\frac{1}{2} \chi(1-\alpha)-(1-\alpha)(1-\psi)}{\chi-(1-\alpha)(1-\psi)}-\frac{\chi(1-\alpha)-(1-\alpha)(1-\psi)}{\chi-(1-\alpha)(1-\psi)} \\
& =\frac{-\frac{1}{2} \chi(1-\alpha)}{\chi-(1-\alpha)(1-\psi)}<0
\end{aligned}
$$

\section{Proof of Proposition 3}

As $\tau^{* *}>0$, it is obvious that the tax policy improves worker's welfare while it reduces entrepreneur's welfare. Following the proof of Proposition 2, worker's welfare with an optimal tax rate $\tau^{* *}$ is: 


$$
\begin{aligned}
u_{1}^{w}= & (1+\beta) \log \left[\left(1-\tau^{* *}\right)(1-\alpha)(1-\psi)+\tau^{* *} \chi\right]\left[\frac{\psi \phi^{E *}\left(1-\tau^{* *}\right) \chi^{1-\alpha}}{\left(1+\beta^{-1}\right)(1+z)(1+v)}\right]^{\frac{\alpha}{1-\alpha}} \chi^{-\alpha} \\
& +\log \frac{1}{1+\beta}+\beta \log \frac{R}{1+\beta^{-1}}
\end{aligned}
$$

Worker's welfare without the tax policy is:

$$
\begin{aligned}
u_{2}^{w}= & (1+\beta) \log [(1-\alpha)(1-\psi)]\left[\frac{\psi \phi^{E *} \chi^{1-\alpha}}{\left(1+\beta^{-1}\right)(1+z)(1+v)}\right]^{\frac{\alpha}{1-\alpha}} \chi^{-\alpha} \\
& +\log \frac{1}{1+\beta}+\beta \log \frac{R}{1+\beta^{-1}}
\end{aligned}
$$

Thus, given that $\tau^{* *}=\frac{\frac{1}{2} \chi(1-\alpha)-(1-\alpha)(1-\psi)}{\chi-(1-\alpha)(1-\psi)}$,

$$
\begin{aligned}
u_{1}^{w}-u_{2}^{w}= & (1+\beta)\left\{\frac{\alpha}{1-\alpha} \log \left(1-\tau^{* *}\right)+\log \left[\left(1-\tau^{* *}\right)(1-\alpha)(1-\psi)+\tau^{* *} \chi\right]\right. \\
& -\log (1-\alpha)(1-\psi)\} \\
= & (1+\beta)\left\{\frac{\alpha}{1-\alpha} \log \frac{\chi-\frac{1}{2} \chi(1-\alpha)}{\chi-(1-\alpha)(1-\psi)}+\log \frac{1}{2}(1-\alpha) \chi-\log (1-\alpha)(1-\psi)\right\} \\
= & (1+\beta) \log \left(\frac{\chi-\frac{1}{2} \chi(1-\alpha)}{\chi-(1-\alpha)(1-\psi)}\right)^{\frac{\alpha}{1-\alpha}} \frac{\frac{1}{2} \chi}{(1-\psi)}
\end{aligned}
$$

Similarly, entrepreneur's welfare with an optimal tax rate $\tau^{* *}$ is:

$$
\begin{aligned}
u_{1}^{E}= & (1+\beta) \log \alpha \frac{(1-\psi)\left(1+\beta^{-1}\right)}{\psi}(1+z)(1+v)\left[\frac{\psi\left(1-\tau^{* *}\right) \chi^{1-\alpha}}{\left(1+\beta^{-1}\right)(1+z)(1+v)}\right]^{\frac{1}{1-\alpha}} \\
& +\left[\frac{\alpha(1+\beta)}{1-\alpha}-\beta\right] \log \phi^{E *}+\log \left(\frac{\psi}{(1+\beta) \alpha(1-\psi)}\right)+\beta \log (1+v)
\end{aligned}
$$

Entrepreneur's welfare without the tax policy is:

$$
\begin{aligned}
u_{2}^{E}= & (1+\beta) \log \alpha \frac{(1-\psi)\left(1+\beta^{-1}\right)}{\psi}(1+z)(1+v)\left[\frac{\psi \chi^{1-\alpha}}{\left(1+\beta^{-1}\right)(1+z)(1+v)}\right]^{\frac{1}{1-\alpha}} \\
& +\left[\frac{\alpha(1+\beta)}{1-\alpha}-\beta\right] \log \phi^{E *}+\log \left(\frac{\psi}{(1+\beta) \alpha(1-\psi)}\right)+\beta \log (1+v)
\end{aligned}
$$

Given that $\tau^{* *}=\frac{\frac{1}{2} \chi(1-\alpha)-(1-\alpha)(1-\psi)}{\chi-(1-\alpha)(1-\psi)}$,

$$
\begin{aligned}
u_{1}^{E}-u_{2}^{E} & =(1+\beta) \frac{1}{1-\alpha} \log \left(1-\tau^{* *}\right) \\
& =(1+\beta) \log \left(\frac{\chi-\frac{1}{2} \chi(1-\alpha)}{\chi-(1-\alpha)(1-\psi)}\right)^{\frac{1}{1-\alpha}}
\end{aligned}
$$




\section{Proof of Proposition 4}

Following the proof of Proposition 2, the social welfare with an optimal tax rate $\tau^{* *}$ is:

$$
\begin{aligned}
W_{1}= & (1+\beta) \log \left[\left(1-\tau^{* *}\right)(1-\alpha)(1-\psi)+\tau^{* *} \chi\right]\left[\frac{\psi \phi^{E *}\left(1-\tau^{* *}\right) \chi^{1-\alpha}}{\left(1+\beta^{-1}\right)(1+z)(1+v)}\right]^{\frac{\alpha}{1-\alpha}} \chi^{-\alpha} \\
& +(1+\beta) \log \alpha \frac{(1-\psi)\left(1+\beta^{-1}\right)}{\psi}(1+z)(1+v)\left[\frac{\psi\left(1-\tau^{* *}\right) \chi^{1-\alpha}}{\left(1+\beta^{-1}\right)(1+z)(1+v)}\right]^{\frac{1}{1-\alpha}} \\
& +\log \frac{1}{1+\beta}+\beta \log \frac{R}{1+\beta^{-1}}+\left[\frac{\alpha(1+\beta)}{1-\alpha}-\beta\right] \log \phi^{E *} \\
& +\log \left(\frac{\psi}{(1+\beta) \alpha(1-\psi)}\right)+\beta \log (1+v)
\end{aligned}
$$

The social welfare without the tax policy is:

$$
\begin{aligned}
W_{2}= & (1+\beta) \log [(1-\alpha)(1-\psi)]\left[\frac{\psi \phi^{E *} \chi^{1-\alpha}}{\left(1+\beta^{-1}\right)(1+z)(1+v)}\right]^{\frac{\alpha}{1-\alpha}} \chi^{-\alpha} \\
& +(1+\beta) \log \alpha \frac{(1-\psi)\left(1+\beta^{-1}\right)}{\psi}(1+z)(1+v)\left[\frac{\psi \chi^{1-\alpha}}{\left(1+\beta^{-1}\right)(1+z)(1+v)}\right]^{\frac{1}{1-\alpha}} \\
& +\log \frac{1}{1+\beta}+\beta \log \frac{R}{1+\beta^{-1}}+\left[\frac{\alpha(1+\beta)}{1-\alpha}-\beta\right] \log \phi^{E *} \\
& +\log \left(\frac{\psi}{(1+\beta) \alpha(1-\psi)}\right)+\beta \log (1+v)
\end{aligned}
$$

The social welfare without housing bubbles is (i.e. $\phi^{E}=1$ ):

$$
\begin{aligned}
W_{3}= & (1+\beta) \log [(1-\alpha)(1-\psi)]\left[\frac{\psi \chi^{1-\alpha}}{\left(1+\beta^{-1}\right)(1+z)(1+v)}\right]^{\frac{\alpha}{1-\alpha}} \chi^{-\alpha} \\
& +(1+\beta) \log \alpha \frac{(1-\psi)\left(1+\beta^{-1}\right)}{\psi}(1+z)(1+v)\left[\frac{\psi \chi^{1-\alpha}}{\left(1+\beta^{-1}\right)(1+z)(1+v)}\right]^{\frac{1}{1-\alpha}} \\
& +\log \frac{1}{1+\beta}+\beta \log \frac{R}{1+\beta^{-1}}+\log \left(\frac{\psi}{(1+\beta) \alpha(1-\psi)}\right)+\beta \log (1+v)
\end{aligned}
$$

Thus, given that $\tau^{* *}=\frac{\frac{1}{2} \chi(1-\alpha)-(1-\alpha)(1-\psi)}{\chi-(1-\alpha)(1-\psi)}$,

$$
\begin{aligned}
W_{1}-W_{2}= & (1+\beta)\left\{\frac{1+\alpha}{1-\alpha} \log \left(1-\tau^{* *}\right)+\log \left[\left(1-\tau^{* *}\right)(1-\alpha)(1-\psi)+\tau^{* *} \chi\right]\right. \\
& -\log (1-\alpha)(1-\psi)\} \\
= & (1+\beta)\left\{\frac{1+\alpha}{1-\alpha} \log \frac{\chi-\frac{1}{2} \chi(1-\alpha)}{\chi-(1-\alpha)(1-\psi)}+\log \frac{1}{2}(1-\alpha) \chi-\log (1-\alpha)(1-\psi)\right\} \\
= & (1+\beta) \log \left(\frac{\chi-\frac{1}{2} \chi(1-\alpha)}{\chi-(1-\alpha)(1-\psi)}\right)^{\frac{1+\alpha}{1-\alpha}} \frac{\frac{1}{2} \chi}{(1-\psi)}
\end{aligned}
$$




$$
\begin{aligned}
& \text { If }\left(\frac{\chi-\frac{1}{2} \chi(1-\alpha)}{\chi-(1-\alpha)(1-\psi)}\right)^{\frac{1+\alpha}{1-\alpha}} \frac{\frac{1}{2} \chi}{(1-\psi)}>1 \text {, then } W_{1}>W_{2} . \\
& \begin{aligned}
W_{2}-W_{3} & =\left[\frac{\alpha(1+\beta)}{1-\alpha}-\beta\right] \log \phi^{E *}+\frac{\alpha(1+\beta)}{1-\alpha} \log \phi^{E *} \\
& =\left[\frac{2 \alpha(1+\beta)}{1-\alpha}-\beta\right] \log \phi^{E *}=(1+\beta)\left[\frac{2 \alpha}{1-\alpha}-\frac{\beta}{1+\beta}\right] \log \phi^{E *}
\end{aligned}
\end{aligned}
$$

Thus,

$$
\begin{aligned}
& W_{1}-W_{3}=\left(W_{1}-W_{2}\right)+\left(W_{2}-W_{3}\right) \\
& =(1+\beta) \log \left(\frac{\chi-\frac{1}{2} \chi(1-\alpha)}{\chi-(1-\alpha)(1-\psi)}\right)^{\frac{1+\alpha}{1-\alpha}} \frac{\frac{1}{2} \chi}{(1-\psi)}\left(\phi^{E *}\right)^{\frac{2 \alpha}{1-\alpha}-\frac{\beta}{1+\beta}} \\
& \text { If }\left(\frac{\chi-\frac{1}{2} \chi(1-\alpha)}{\chi-(1-\alpha)(1-\psi)}\right)^{\frac{1+\alpha}{1-\alpha}} \frac{\frac{1}{2} \chi}{(1-\psi)}\left(\phi^{E *}\right)^{\frac{2 \alpha}{1-\alpha}-\frac{\beta}{1+\beta}}>1 \text {, then } W_{1}>W_{3} \text {. }
\end{aligned}
$$

